OPEN ACCESS

Edited by:

Wei $L v$,

Tsinghua University, China

Reviewed by:

Huan Li,

University of Adelaide, Australia

Yang $L i$,

Tianjin University, China

*Correspondence: Francisco J. García-Mateos garciamateos@uma.es

Specialty section: This article was submitted to

Carbon-Based Materials, a section of the journal

Frontiers in Materials

Received: 15 February 2019 Accepted: 07 May 2019 Published: 24 May 2019

Citation: García-Mateos FJ, Ruiz-Rosas $R$ Rosas JM, Rodríguez-Mirasol J and Cordero T (2019) Controlling the Composition, Morphology, Porosity, and Surface Chemistry of

Lignin-Based Electrospun Carbon

Materials. Front. Mater. 6:114.

doi: 10.3389/fmats.2019.00114

\section{Controlling the Composition, Morphology, Porosity, and Surface Chemistry of Lignin-Based Electrospun Carbon Materials}

\author{
Francisco J. García-Mateos *, Ramiro Ruiz-Rosas, Juana M. Rosas, \\ José Rodríguez-Mirasol and Tomás Cordero
}

Departamento de Ingeniería Química, Facultad de Ciencias, Universidad de Málaga, Andalucía Tech, Málaga, Spain

Electrospinning is a suitable top-down technique for the preparation of polymeric fibers using high voltage electrical fields and solutions of the selected polymer of adequate viscosity and conductivity. The versatility of electrospinning allows accurate control of the morphology and composition of the fibers by a wide combination of operating conditions and small modifications of the spinneret and collector. Alcell lignin, which is extracted from lignocellulosic biomass using organic solvents through Organosolv process, is readily solved in ethanol, producing a solution that matches the requirements of the electrospinning process. This review summarizes the vast collection of carbon materials that can be obtained by processing lignin using electrohydrodynamic forces. The coaxial and triaxial electrospinning setups allow for obtaining fibers with two or more components hierchically arranged, the use of these configurations along with a carefully setting of the operating conditions (distance between needle and collector, voltage, flow rate, ...) and the solution properties (conductivity, viscosity, ...) facilitates the conformation of lignin into spheres, beaded fibers, straight fibers and fused meshes. All these morphologies can be implemented with solid or hollow bodies (i.e., enabling the production of tubes and hollow spheres) by using a sacrificial templating agent. Phosphoric acid can also be added in small amounts to the lignin solution, shortening the thermostabilization time of the fibers. The porosity of the phosphorus containing carbon fibers can be modified in the last stage of the preparation of carbon fibers by controlled gasification process, owing to the extended oxidation resistance of the P-doped fibers. Fibrillar carbon catalysts can be also obtained by one-pot preparation method, only solving small quantities of metallic salts in the lignin solution. All these carbon materials were successfully tested in different applications such as heterogeneous catalysis, energy storage and environmental protection, confirming that electrospinning is a powerful tool for maximizing the value of lignin as carbon precursor.

Keywords: lignin, electrospinning, $\mathrm{H}_{3} \mathrm{PO}_{4}$, fiber morphology, fast stabilization, one-post synthesis catalysts, supercapacitors 


\section{INTRODUCTION}

Lignin is one of the three main building blocks of lignocellulosic materials. The lignin structure depends on the feedstock, with softwood, hardwood and other vegetation having different lignin contents, and characteristics. In general, it can be supposed to be a random three-dimensional polymer of phenylpropane units linked together, reason why it is also considered the most abundant source of renewable aromatics on Earth. Industrially, lignin can be produced from different processes, obtaining the corresponding Kraft lignin (KL), Soda lignin, Lignosulphonates (LS), Organosolv lignins (OS), Steam-explosion lignin, and enzymatic hydrolysis lignin (EHL). These lignins also present different chemical structures and properties.

Large scale production of lignin is mainly associated to pulp and paper industry and bioethanol production in wood-toethanol biorefineries as by-product. In this context, only around $40 \%$ of the generated lignin is needed to cover the internal energy demand of a biorefinery. Apart from this combustion, lignin can be directly used as dispersant, emulsifier, binder, animal feed, and utilized as raw material for the production of synthetic vainillin, but according to Global Lignin Products Market 20172021 report "The latest trend gaining momentum in the market is increasing application of lignin in newer applications." ${ }^{1}$ In this sense, lignocellulosic biorefineries are looking for opportunities to valorize the lignin by-products in high-value products instead of direct energy production to improve cost-competitiveness.

An important drawback to diversify the application of lignin at an industrial scale is related to the fact that most types of lignin are only soluble in water at alkaline $\mathrm{pH}$ and that many of the process to obtain lignin use very harsh conditions. With this regard, the Alcell ${ }^{\circledR}$ pulping process (the most well-known process in the organosolv lignin category) produces lignin soluble in non-toxic organic solvents, such as ethanol, with very low amount of impurities, and more environmentally friendly than others. These properties along with the carbon-rich and high aromatic content of lignin become it a very interesting raw precursor for the preparation of carbon materials with high value added (Rosas et al., 2014).

Among the different options, the preparation of carbon fibers (CFs) from lignin can be considered a very attractive option (Leitten et al., 2002; Frank et al., 2014; Ragauskas et al., 2014; Fang and Smith, 2016). CFs are materials, typically derived from conventional fossil precursors (PAN and pitches), with different advantages such as their low density with a very high strength to weight ratio, high tensile strength, low thermal expansion, high electrical conductivity... Nevertheless, the high manufacture cost, scarcity and growing demand require the look for others raw materials, preferentially less expensive, more abundant and sustainable than PAN and pitches. Specifically, the leading country based on carbon fiber production capacity in 2018 was USA with 45,300 metric tons (MT), followed by

\footnotetext{
${ }^{1}$ https://www.researchandmarkets.com/reports/4403355/global-lignin-productsmarket-2017-2021
}

Japan, accounting for almost half of the production of USA ${ }^{2}$. However, the high worldwide production rate of carbon fibers is not expected to be enough to meet the demand in 2020, with an estimation of 150,200 MT vs. 129,965 of manufacturing $^{3}$. In this context, the use of lignin as renovable precursor would reduce the manufacture cost of CFs and would also provide an alternative route for lignin valorization (Leitten et al., 2002; Frank et al., 2014; Ragauskas et al., 2014; Fang and Smith, 2016). Specifically, our research group has extensively studied the use of Alcell lignin for this purpose (Lallave et al., 2007; Ruiz-Rosas et al., 2010; Berenguer et al., 2016b; García-Mateos et al., 2017, 2018a).

Generally, the production of lignin CFs implies different steps: (i) purification of lignin and preparation of the spinning solution (if necessary), the low presence of impurities in Alcell lignin and the total solubility in ethanol facilitates this step; (ii) spinning into lignin fibers, which can be carried out by wet-, dry -(Fukuoka, 1969), melt- (Mikawa, 1970), and electrospinning methods (Lallave et al., 2007; Ruiz-Rosas et al., 2010); (iii) oxidative thermostabilization of as-spun lignin fibers to avoid their fusion in subsequent steps, this is one of the key aspects of the manufacture due to the large time required in this step; (iv) carbonization treatment to generate the lignin-based CFs; and finally (v) further treatments in order to enhance their properties for structural and/or functional applications.

Although dry- and wet spinning methods were the firsts used to prepare lignin-based CFs (mid-60s), melt spinning has been the most studied. This last method is based on the extrusion of a fusible lignin, obtaining very homogeneous carbon fibers. The main drawback of melt spinning arises from the very specific lignin properties needed in this method to avoid cross-linking during extrusion, at high stabilization rates. The achievement of these suitable properties is the main objective of the latest research, mainly focused on purification treatments, plasticization with additives, and/or chemically modifications of isolated lignin (Rosas et al., 2014).

Electrospinning is a simple and versatile technique which allows for obtaining lignin-based carbon fibers, using high voltage electrical fields and solutions of the selected polymer of adequate viscosity and conductivity. Most lignin solutions have shown low spinnability, requiring the addition of a plasticizing additive to prevent bead formation and/or electrospray (Dallmeyer et al., 2010, 2014a; Hosseinaei and Baker, 2012). However, our research group has been able to produce lignin based CFs without the incorporation of any spinning-assisted agent, at room temperature and without chemical modifications, reducing the manufacture complexity, time and costs (Lallave et al., 2007; Ruiz-Rosas et al., 2010; Berenguer et al., 2016b; García-Mateos et al., 2017, 2018a). The size of the fibers obtained by this technique ranges from $100 \mathrm{~nm}$ to a few microns, what fills the gap between nanofibers prepared by chemical vapor deposition and fibers prepared by conventional extrusion methods. The versatility of electrospinning allows an accurate

\footnotetext{
${ }^{2}$ https://www.statista.com/statistics/380549/leading-countries-by-carbon-fiberproduction-capacity/

${ }^{3}$ https://www.compositesworld.com/articles/supply-and-demand-advancedfibers- 2016
} 
control of the morphology and composition of the fibers, from which it is possible to obtain pure or doped lignin derived CFs with different heteroatoms, only by adding the corresponding heteroatom to the lignin solution (in this case in ethanol); solid and/or hollow lignin derived CFs, and even ceramic/lignin composite fibers, only with a few modifications of the configuration set-up (coaxial and triaxial configurations).

The main objective of this work consists of demonstrating the different possibilities of carbon materials that can be obtained by processing lignin using electrohydrodynamic forces. The basic of electrospinning are described, as well as the most relevant parameters controlling the morphology and size of the electrospun fibers. In this sense, coaxial, and triaxial electrospinning configurations are highlighted as versatile ways for controlling the structure and composition of electrospun fibers. A review of the contribution to the preparation of lignin fibers/tubes by electrospinning made by our research group is presented, showing examples from our research about the available possibilities for controlling the structure, porosity, surface chemistry, and composition of electrospun carbon fibers. Lastly, we analyze the addition of precursors and porosity promoters in the lignin solution, what allows one-pot synthesis of phosphorus and/or metal-containing carbon fibers. Some applications of electrospun carbon fibers in the field of catalysis, adsorption, and energy storage are also reported as evidences of the advantages of combining lignin, a green carbon precursor, with electrospinning, a versatile top-down nanofiber production method.

\section{ELECTROSPINNING AS A TOOL TO PRODUCE POLYMER, CARBON AND INORGANIC NANOFIBERS}

Electrospinning is one of the most suitable techniques for the preparation of continuous polymeric fibers with diameters sizing from a few microns down to a few tens of nanometers. There are different reviews in the recent literature that summarize the main principles of this technique (Huang et al., 2003; Cavaliere et al., 2011; Inagaki et al., 2012; Kenry and Lim, 2017; Xue et al., 2017). Briefly, a highly concentrated solution of the polymer to be spun is prepared using a volatile solvent. This solution is pumped through the spinneret at a fixed flow rate. The spinneret is connected to a high voltage power supply (in the range of $\mathrm{kV}$ ). A grounded metallic collector is placed at short distance (a few tens of centimeters) from the spinneret. Under the application of a high electric field, the solution exiting the spinneret becomes charged. The interaction between electrohydrodynamic forces (namely the surface tension and the electrostatic repulsion) deforms the droplet at the tip of the spinneret into a conical shape called the Taylor cone. When the applied voltage exceeds the critical value, repulsive forces overcome the surface tension and a micrometric jet of the polymeric solution is ejected from the tip of the Taylor cone and flies toward the grounded collector. The repulsive forces propelling the jet can also generate a whipping or bending instability, enlarging the trajectory from the spinneret to the collector and stretching the jet diameter down to the nanometer scale. Eventually, the liquid jet can break up to form a spray of charged microdrops, in what is known as electrospray (Cloupeau and Prunet-Foch, 1994), a technique with highly interesting applications such as thin film production or drug encapsulation, among many others. Given that the repulsive forces are not strong enough to break the jet in short times, and due to the solvent evaporates at fast rate (owing to a high volatility and a large specific surface area of the jet), solid fibers are formed during the fly deposited at the top of the collector surface. As a result, non-woven mats of nanoscale fibers are formed on the collector. It must be highlighted that certain polymer fibers can be heat treated and transformed into electrospun carbon nanofibers (Inagaki et al., 2012). Moreover, inorganic nanofibers can be also attained by using partially gelated solutions from inorganic alkoxides or by mixing the salt precursors into a polymer solution that would be latter removed by calcining the fiber (Xue et al., 2017).

\section{Parameters Governing the Size and Morphology of Electrospun Fibers}

It is important to note that the size of the fibers obtained by electrospinning is independent of the diameter of the nozzle, and it is instead controlled by electrospinning parameters (GañánCalvo et al., 1997). In fact, there are parameters related to the solution properties, such as the polymer concentration, the electrical conductivity, the viscosity and the surface tension of the solution, which must be set within a range of adequate values for enabling the electrospinning of the polymer solution (Hohman et al., 2001). Once the spinnable solution is obtained, some other process parameters can be tuned to modify the size and morphology of the nanofibers, like solution flow rate, voltage, nozzle to collector distance, humidity, and temperature. In principle, size of the fiber decreases with polymer concentration (Beachley and Wen, 2009; Inagaki et al., 2012). For polymers showing low conductivity, the electrical conductivity of the solution is usually dictated by the conductivity of the solvent; in such cases, the size of the electrospun fibers decrease with conductivity (Tan et al., 2005). Additives that increase the solution conductivity, like salts or conductive polymers, can be also included and have been proven to decrease fiber size (Son et al., 2004). Other parameters such as feed rate and voltage seem to drive the fiber morphology rather than the fiber diameter (Deitzel et al., 2001), while surface tension and viscosity are related to the polymer concentration, what hinders their actual impact into the fiber diameter. For instance, high viscosity values are known to increase the size of the obtained fibers, but in most cases such high viscosity is achieved by increasing the polymer concentration in the solution (Mituppatham et al., 2004). With regard to the morphology, low viscosity, low polymer concentration, high surface tension, and high voltages increase the occurrence of beaded fibers due to the preponderance of surface tension over viscoelasticity of the jet (Fong et al., 1999; Mit-uppatham et al., 2004; Son et al., 2004). Increase of the solution conductivity via the addition of salts can avoid the formation of beaded fibers without increasing the polymer concentration, thus reducing the minimum diameter 
of smooth fibers (Fong et al., 1999). Ambient parameters like temperature and humidity modify the evaporation rate of the solvent, and accordingly can improve the spinnability of the solution. However, excessively fast evaporation rate can also dry the solution at the tip of the nozzle, clogging the system after several minutes of operation.

\section{Modification of the Electrospinning Setup: Coaxial and Triaxial Electrospinning}

The basic electrospinning setup can be easily customized, what is useful for different purposes (Teo and Ramakrishna, 2006). For instance, melt electrospinning can be used for production of fibers from pure polymers with a better control of fiber alignment and placement (Brown et al., 2016), while needleless electrospinning allows to produce electrospun fibers avoiding the use of syringe pumps (Sabantina et al., 2018). Another variation consists of modifying the collector placement, shape or the ability to rotate. In this sense, the use of rotatory drums is a popular choice, since it allows to impose a predominant fiber orientation on the collected mats (Fennessey and Farris, 2004). Several modifications of the needle and collector placements have been also tested for attaining controllable fiber alignment (Pan et al., 2006).

The spinneret configuration is another source of the flexibility in electrospinning. In this sense, the preparation of electrospun fibers in core-sheath mode with two different materials has been made possible by using two coaxial needles in the spinneret in what is known nowadays as coaxial electrospinning. This setup was first reported by Loscertales et al. (2002) for the encapsulation of liquids, and was later modified for production of silica nanotubes by flowing a partially gelated tetraethyortosilicate (TEOS) solution through the outer needle while feeding a synthetic oil, that served as the template for the hollow core of the tube, through the inner needle (Larsen et al., 2003). Coaxial electrospinning allows to produce a steady compound jet formed by two immiscible liquids that are pumped through the outer and the inner needles. Coaxial electrospinning has remarkable advantages over the conventional setup, such as: (i) hollow fibers can be prepared using a sacrificial solution that is feed through the inner needle; (ii) composite fibers with coreshell structure can be obtained by feeding the outer and inner needle with two different solutions; (iii) it allows the preparation of fibers from a non-spinnable solution by using a spinnable one, which favors the formation of the Taylor cone.

\section{PRODUCTION OF CARBON FIBERS AND TUBES BY ELECTROSPINNING OF LIGNIN SOLUTIONS}

The benefits of using lignin as carbon precursor were pointed out in the introduction section. In fact, conventional spinning methods were able to achieve carbon fibers from lignin with sizes ranging in ten of microns. In contrast, electrospinning made possible to produce carbon fibers with sizes below the microns. In 2007, our research group reported for the first time the production of carbon fibers from electrospun lignin fibers
(Lallave et al., 2007). For this purpose, Alcell lignin/ethanol solutions of $1 / 1$ weight ratios were prepared. The use of a high concentration of lignin was necessary to get an appropriate viscosity, avoiding the predominance of the Rayleigh instability that leads to early breakage of the jet, producing electrospray.

Unfortunately, a conventional electrospinning setup only operating with the lignin/ethanol solution produced the clogging of the needle tip after a few minutes, stopping the process. The fast evaporation rate of ethanol at the tip of the needle and the high lignin concentration were responsible of this undesired outcome. The use of a coaxial electrospinning was mandatory to get a continuous electrospinning of lignin fibers. In this case, the addition of ethanol through the outer needle compensated the solvent losses at the tip of the needle, allowing to achieve a steady Taylor cone formation. In fact, an adequate selection of the relative flow rate ratios of the ethanol and the lignin solution can be used to tune the morphology obtained on top of the collector surface. Figure 1 compiles a collection of SEM images obtained by coaxial electrospinning of Alcell lignin/ethanol solutions (0.8:1 weight ratio). These micrographs show the different morphologies that can be obtained by only modifying the ethanol flow rate of the outer needle to values of $30 \%$ (Figure 1A), 20\% (Figure 1B), and 10\% (Figure 1C) of that of the inner needle (lignin solution). The remarkable transition from spheres to beaded fibers and finally solid fibers illustrates the versatility of electrohydrodynamic forces, and specifically of the coaxial electrospinning setup, in controlling the shape of the resulting materials. These morphologies are highly desirable for membrane, controlled drug release and bioengineering applications (Lannutti et al., 2007; Hu et al., 2014; Ahmed et al., 2015).

Most works regarding the preparation of electrospun lignin fibers reports the use of binders as polyethylene oxide or polyvinyl pyrrolidone (Dallmeyer et al., 2010; Hu and Hsieh, 2013; Wang et al., 2013; Lai et al., 2014). In our case, it must be highlighted that shaping lignin into fibers is attained without the addition of any binder or other type of additive in this method. This enhancement is derived from the suitable properties of Alcell lignin, such as high purity and solubility in ethanol, which enable to reach high lignin concentrations, and hence high viscosity of the solution.

When directly carbonized, lignin fibers melt as soon as their glass transition temperature (Tg) is surpassed. The electrospun Alcell Lignin fibers are submitted to an air treatment at $200^{\circ} \mathrm{C}$, which is reached using low heating rates $\left(\mathrm{ca} .5^{\circ} \mathrm{C} / \mathrm{h}\right)$ to favor the partial oxidation of the lignin chains. This oxidative treatment generates ether groups bridging the lignin polymeric chains. These crosslinking and condensation reactions increase $\mathrm{Tg}$, enabling to obtain carbon fibers on a subsequent treatment under inert atmosphere at temperatures ranging from 600 to $1,000^{\circ} \mathrm{C}$ (Ruiz-Rosas et al., 2010). Thus, carbonization of the stabilized lignin fibers under inert atmosphere using a heating rate of $10^{\circ} \mathrm{C} / \mathrm{min}$ was successful obtained without deteriorating their morphology and attaining preparation yields as high as $30 \%$ at $900^{\circ} \mathrm{C}$. Carbonization at such different temperatures rendered carbon fibers with a variety of surface oxygen groups and different micropore volumes and specific surface areas $\left(\mathrm{S}_{\mathrm{BET}}\right)$. 

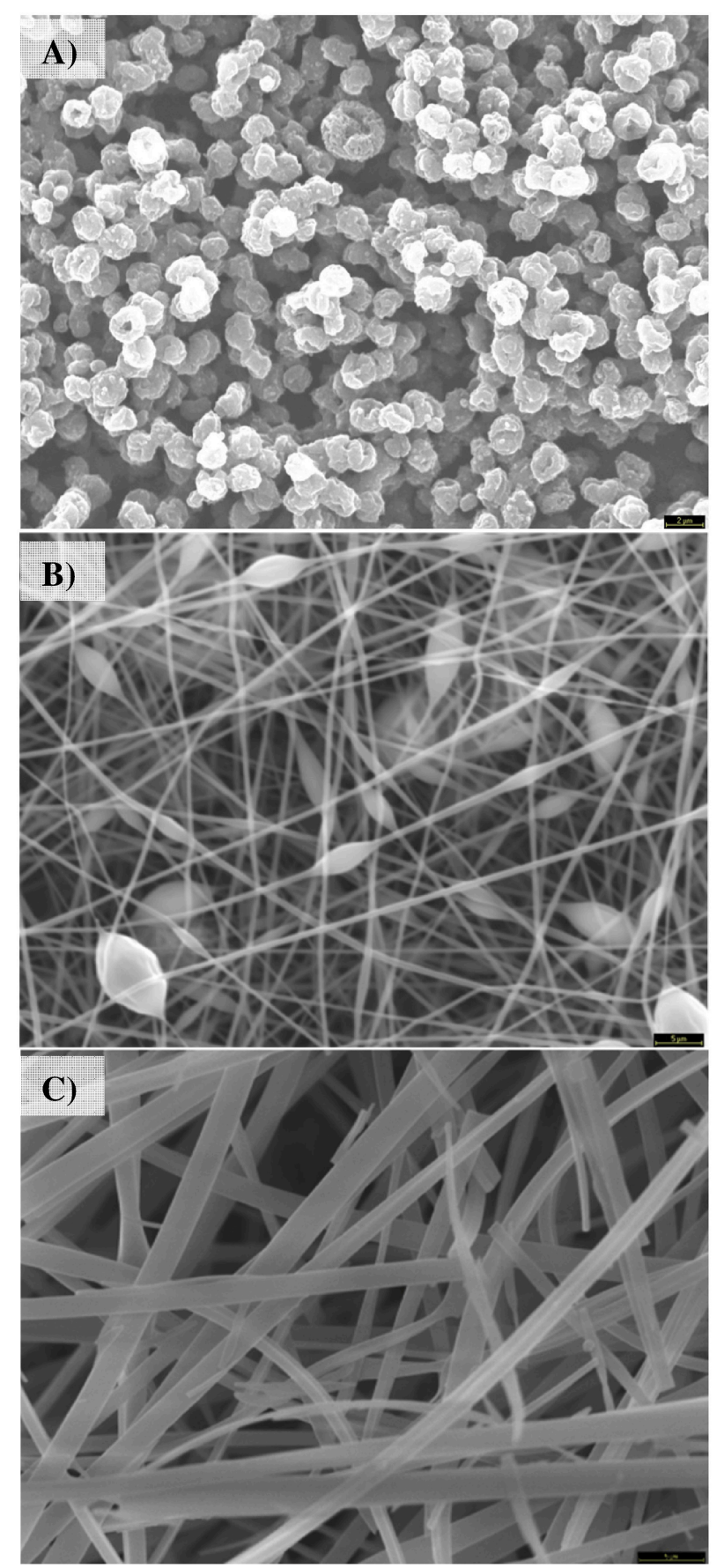

FIGURE 1 | SEM images of lignin (A) spheres (scale bar: $2 \mu \mathrm{m}$ ); (B) beaded fibers (scale bar: $5 \mu \mathrm{m}$ ); and $\mathbf{( C )}$ linear fibers (scale bar: $5 \mu \mathrm{m}$ ).

The resulting materials consisted of flexible carbonized mats (thickness of $<1 \mathrm{~mm}$ ). Interestingly, the carbonized fibers show a high development of narrow micropores with sizes around $0.7 \mathrm{~nm}$, as pointed out by the similar micropore volumes obtained by the $\mathrm{N}_{2}$ adsorption isotherm at $-196^{\circ} \mathrm{C}$ and $\mathrm{CO}_{2}$ adsorption isotherm at $0^{\circ} \mathrm{C}$, without needing additional activation steps. No mesopore volume is developed, and the external surface area, measured by t-plot or $\alpha$-s method, is in agreement to the geometric surface area of the carbonized fibers. The microporosity generation is related to the high oxygen content of Alcell lignin, which is further increased in the air stabilization treatment. The oxygen surface groups of the stabilized fibers evolve in the form of $\mathrm{CO}$ and $\mathrm{CO}_{2}$ during the thermal treatment, which produces a significant gasification of the carbon fibers. In accordance to a larger removal of oxygen groups at higher carbonization temperatures, the micropore volume and apparent surface area increase with the carbonization temperature from 600 to $900^{\circ} \mathrm{C}$, reaching a maximum at ca. $0.4 \mathrm{~cm}^{3} / \mathrm{g}$, with a corresponding $\mathrm{S}_{\mathrm{BET}}$ of around $1,100 \mathrm{~m}^{2} / \mathrm{g}$. Increasing the carbonization temperature to $1,000^{\circ} \mathrm{C}$ produces the shrinkage of the porosity, because most of functional oxygen groups are removed at $900^{\circ} \mathrm{C}$, easing the stacking and condensation of carbon microcrystallites. The possibility of obtaining highly ordered carbon materials from the direct carbonization of lignin was reported by our research group elsewhere (RodríguezMirasol et al., 1996). In this sense, Raman spectroscopy of the carbonized fibers at relatively high temperature (around $900^{\circ} \mathrm{C}$ ) revealed a low $I_{D} / I_{G}$ ratio, indicative of the presence of an incipient graphite-like structural order.

Carbon microtubes are another interesting morphology, due to their improved mass transfer rate, which can be obtained from electrospinning of lignin (Lallave et al., 2007). For this purpose, a tri-axial electrospinning configuration was constructed. Figure 2 compares the co-axial and tri-axial electrospinning. As can be seen in this figure, the new experimental set-up can be viewed as a modification of the co-axial electrospinning, where a new smaller needle is emplaced inside the old inner needle, allowing to feed a different solution in the core of the lignin solution. A high viscosity solution that is immiscible in ethanol is flown through the new inner needle, so that a compound core/sheath Taylor cone is generated, with the spinnable lignin/ethanol solution flowing as the sheath and pulling from the immiscible solution at the core position. If the innermost compound (i.e., the one in the high viscosity solution) is selectively removed after the fiber collection without compromising the lignin sheath, a hollow lignin fiber (i.e., a lignin tube) will be obtained. Following this scheme, two mineral oils with viscosities of 220 and 1,360 cP, the first one has a viscosity lower than lignin solution, $500 \mathrm{cP}$, while the latter one has a higher viscosity. These oils were used as the template of the tube cavity and were feed through the inner needle in the core position (Ruiz-Rosas et al., 2009). Since these oils show boiling points over $300^{\circ} \mathrm{C}$, and they have a high specific heat that can interfere with the stabilization step, the heating rate of the stabilization treatment was slow down to $3^{\circ} \mathrm{C} / \mathrm{h}$. The atmosphere of the stabilization step was also modified to include vacuum-air cycles, where vacuum is applied in order to ease the removal of the oils. The stabilized hollow fibers were carbonized in a similar manner to the solid fibers, under inert atmosphere at $900^{\circ} \mathrm{C}$ using a heating rate of $10^{\circ} \mathrm{C} / \mathrm{min}$.

The viscosity of the oil played an important role on the resulting morphology of the fibers, as depicted by the SEM and TEM micrographs shown in Figure 3. All the materials were obtained fixing the flow rates of the lignin solution, the oil and the ethanol solution to $0.9: 0.3: 0.1 \mathrm{~mL} / \mathrm{h}$, respectively. 
A)

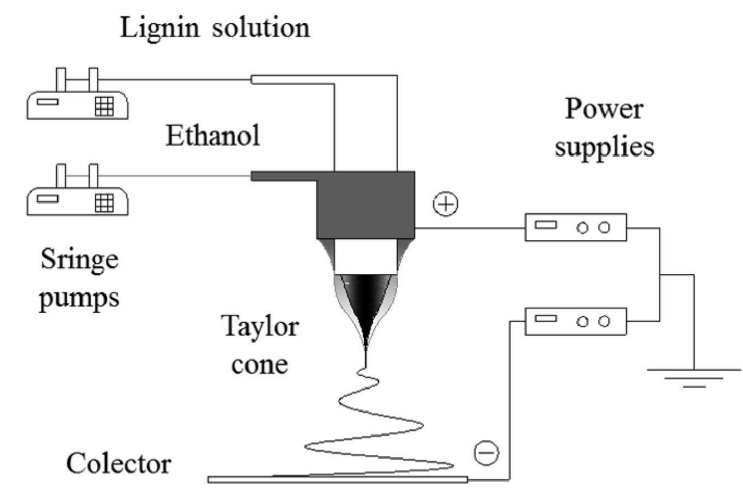

B)

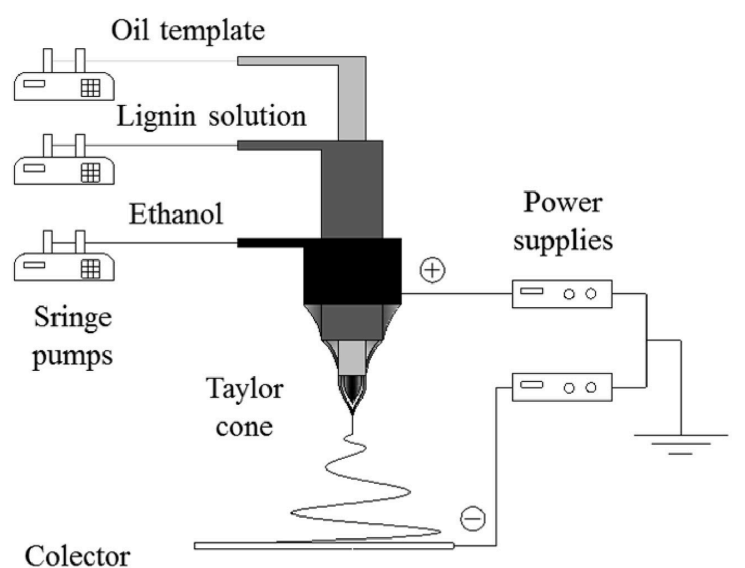

FIGURE 2 | Scheme of (A) co-axial and (B) tri-axial electrospinning for preparing lignin solid fibers and tubes, respectively.

Nevertheless, the use of a low viscosity oil resulted in carbonized fibers with "bean" morphology, Figure 3A, which is different to the classical beaded fibers shown in Figure 1. Specifically, when a low viscosity oil is used, lignin solution broke the jet of the oil into drops, which are contained inside the lignin fibers, meanwhile the viscous forces of the high viscosity oil maintain the inner jet intact until the lignin fibers are collected. Differently, the high viscosity oil provided a continuous jet, resulting in smooth hollow fibers, Figure 3B. TEM images of the same samples collected in Figures 3C,D confirmed the presence of oil encapsulation and continuous hollow carbon fibers, respectively. As in the case of conventional beaded fibers and microspheres, these morphologies could be useful in the fields of membrane science and bio-engineering, where the large and rough surface of bean fibers and the use of a bio-compatible material could be helpful for tissue scaffold applications (Lannutti et al., 2007).

The diameter of the wall of the tube and the size of the cavity of the tube can be easily tuned attending to the flow rate of the high viscosity oil. Figure 4 shows the effect of increasing the oil flow rate from 0.2 to $0.6 \mathrm{~mL} / \mathrm{h}$, keeping constant the lignin solution flow rate at $0.9 \mathrm{~mL} / \mathrm{h}$. The size of the cavity increases at the expense of the wall thickness. The external diameter of the carbon tubes also increases with the oil flow rate. These images evidence the accuracy that can be attained in controlling the morphology and size of microsized materials when using this simple technique.

\section{ELECTROSPUN CARBON FIBERS AS BINDERLESS ELECTRODES OF SUPERCAPACITORS}

These promising properties moved us to test the carbonized electrospun lignin fibers as supercapacitor electrodes (Berenguer et al., 2016b). Supercapacitors are energy storage devices showing high power capability, long durability and medium energy density. However, their cost in terms of energy density is still one

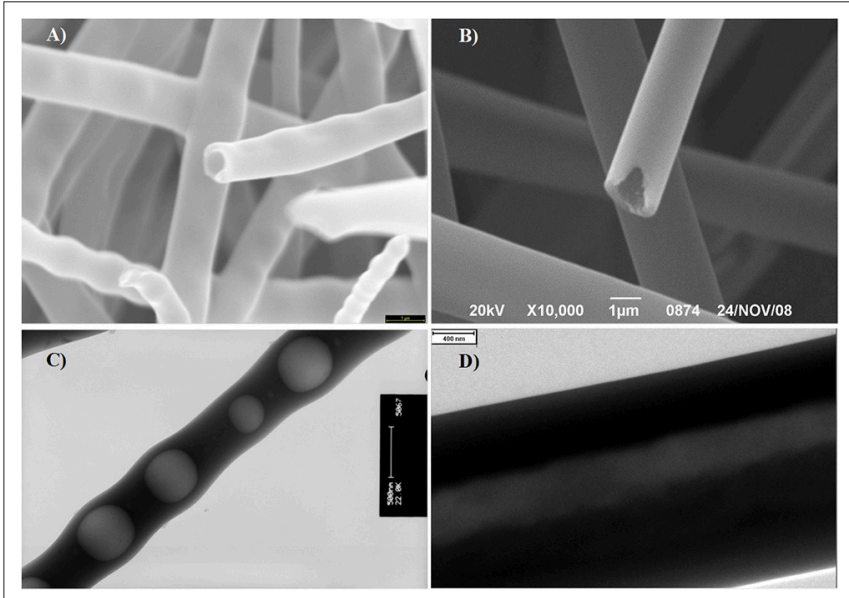

FIGURE 3 | SEM images of carbonized electrospun lignin fibers obtained using (A) a low viscosity oil; and (B) high viscosity oil. Bar lengths: $1 \mu \mathrm{m}$. TEM images of the same carbonized electrospun lignin fibers obtained using $(\mathbf{C})$ the low viscosity oil (bar length: $500 \mathrm{~nm}$ ); and (D) the high viscosity oil (bar length: $400 \mathrm{~nm})$.

order of magnitude larger than that of Li-ion batteries (Miller, 2016), and it needs to be decreased for achieving a widespread use, especially in the case of flexible and portable devices. For the latter application, binderless, seamless, and flexible electrodes are preferred. Unfortunately, most of their synthesis procedures are conceived for the use of nanostructured carbon materials, which are expensive and cannot be easily handled and processed into electrodes, increasing the cost of these devices (Wang et al., 2014). The combination of lignin, as carbon source, and electrospinning, as a simple, top-down technique, for the production of binderless and flexibles electrodes could help in delivering lower production costs in this field (EspinozaAcosta et al., 2018). The carbonized mats prepared at $900^{\circ} \mathrm{C}$ were cut in the desired shape, soaked in $1 \mathrm{M} \mathrm{H}_{2} \mathrm{SO}_{4}$ and 


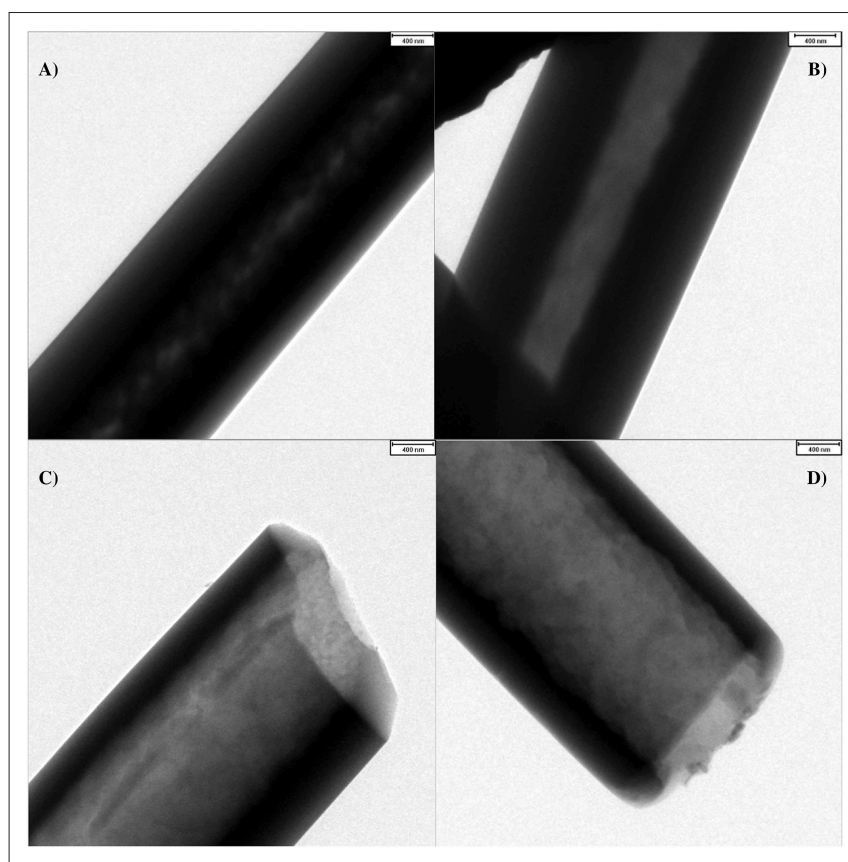

FIGURE 4 | TEM images of carbon fibers obtained from electrospun lignin fibers prepared using an oil flow rate of (A) $0.2 \mathrm{~mL} / \mathrm{h}$; (B) $0.4 \mathrm{~mL} / \mathrm{h}$; (C) 0.5 $\mathrm{mL} / \mathrm{h}$; and (D) $0.6 \mathrm{~mL} / \mathrm{h}$. Scale bar: $400 \mathrm{~nm}$.

directly attached to the current collectors, acting as binderless, flexible electrodes. The electrochemical characterization by cyclic voltammetry of these lignin-based electrodes revealed 3electrode capacitance values of ca. $150 \mathrm{~F} / \mathrm{g}$, box-shaped cyclic voltammetry, characteristic of capacitive materials, and excellent rate performance when the scan rate was increased from 0.01 up to $1 \mathrm{~V} / \mathrm{s}$. The electrochemical stability of the electrodes was also determined, showing a wide potential window (from -0.4 to $1.0 \mathrm{~V}$ vs. $\mathrm{Ag} / \mathrm{AgCl})$. The good electrical conductivity is related to the structural order observed in Raman spectroscopy and to the high carbon fibers interconnectivity of the electrode. A notable decline in the rate performance of the grinded fibers was observed when the electrochemical response of the grinded carbon mat (losing its binderless and free-standing features) was analyzed. This test was carried out by shaping it into an electrode using the traditional mixture, with conductivity promoter and binder, and showed worse electrochemical performance than binderless interconnected carbon fibers. In view of these promising results, two additional modifications were implemented on the preparation of the carbon mats: (i) improvement of the electrode interconnectivity by doubling the heating rate during the air stabilization, what produces partial melting of the stabilized fibers and increases the electrical conductivity with a negligible impact on the porosity development (ii) onestep physical activation of the carbonized lignin fibers using diluted air atmosphere during their carbonization, increasing the surface area by $40 \%$ without additional preparation steps. By combining both modifications, we constructed a symmetric two-electrode supercapacitor showing energy density of 10 $\mathrm{Wh} / \mathrm{kg}$ and maximum power density of $60 \mathrm{~kW} / \mathrm{kg}$ in aqueous electrolyte. The high durability of these carbon fibers was demonstrated when the supercapacitor cell was able to be safely loaded and unloaded at $1.3 \mathrm{~V}$ using $5 \mathrm{~A} / \mathrm{g}$ for 100,000 cycles, showing minor degradation of energy and power densities. The performances shown by these carbon mats were close to the highest ever reported for PAN electrospun binderless electrodes, but using a greener carbon precursor and without requesting additional activation steps.

\section{TUNING THE ELECTROSPINNING SOLUTION FOR THE PREPARATION OF LIGNIN-BASED CARBON FIBERS}

Attending to the modification of the electrospinnign solution, the addition of stabilizer, porosity development and metal salt precursors to the initial lignin solution was studied. In our research group, we have proposed $\mathrm{H}_{3} \mathrm{PO}_{4}$ as stabilizing agent as well as chemical agent to activate the carbon fibers. Furthermore, Pt-containing carbon fibers catalysts were prepared by adding Pt-salt precursor to the initial solution.

\section{Addition of $\mathrm{H}_{3} \mathrm{PO}_{4}$ as Stabilizer and Porosity Development Promoter}

As above mentioned, stabilization is a critical step in the preparation of carbon fibers from lignin due to the low glass transition temperature ( $\mathrm{Tg}$ ) of lignin. To increase $\mathrm{Tg}$, crosslinking and condensation reactions have to be favored. For this purpose, the production of ether groups that bridge the lignin polymeric chains have to be produced by oxidation of the fibers. Due to the importance of the stabilization step, the parameters of lignin fibers stabilization have been studied by many authors (Kadla et al., 2002; Braun et al., 2005; Brodin et al., 2011; Norberg et al., 2013). In this sense, Jagtoyen et al. stablished some time ago that cross-linking and condensation reactions occur when $\mathrm{H}_{3} \mathrm{PO}_{4}$ is mixed with a lignocelullosic material (Jagtoyen and Derbyshire, 1998). Our research group has a vast experience in the preparation of carbon materials from different lignocellulosic raw materials, including lignin, by chemical activation with $\mathrm{H}_{3} \mathrm{PO}_{4}$ (Gonzalez-Serrano et al., 2004; Rosas et al., 2008; Bedia et al., 2011; Cordero-Lanzac et al., 2018). With the objective to promote the cross linking and condensation reactions and the porosity development, the addition of $\mathrm{H}_{3} \mathrm{PO}_{4}$ to the lignin/ethanol solution was studied (García-Mateos et al., 2018a). A low amount of $\mathrm{H}_{3} \mathrm{PO}_{4}$ as stabilizing agent with Alcell lignin and ethanol (weight ratio of $\mathrm{H}_{3} \mathrm{PO}_{4}$ /lignin/ethanol of $0.3 / 1 / 1$ ) was mixed. Using similar electrospinning conditions to those reported for pure lignin fibers, a cotton-like mat consisting of non-woven and continuous microsized fibers were obtained on the collector. XPS and TPD measurements show that the electrospinning of $\mathrm{H}_{3} \mathrm{PO}_{4}$ /lignin/ethanol solutions produces more oxidized lignin fibers. For pure lignin fibers, an increase in the oxygen content (from 26 to $32 \%$ ) after a stabilization step of $100 \mathrm{~h}$ is observed. In contrast, for phosphorus-containing lignin fibers, higher oxygen content (around 28\%) was obtained after the addition of $\mathrm{H}_{3} \mathrm{PO}_{4}$ to the initial lignin/ethanol solution. This higher oxygen contents is associated to the presence of 


\section{Stabilized P-containing lignin fibers}
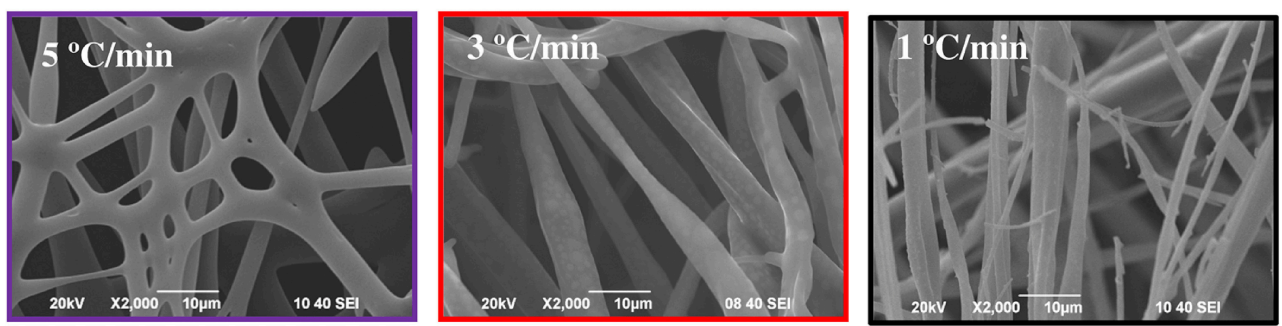

Time (min)
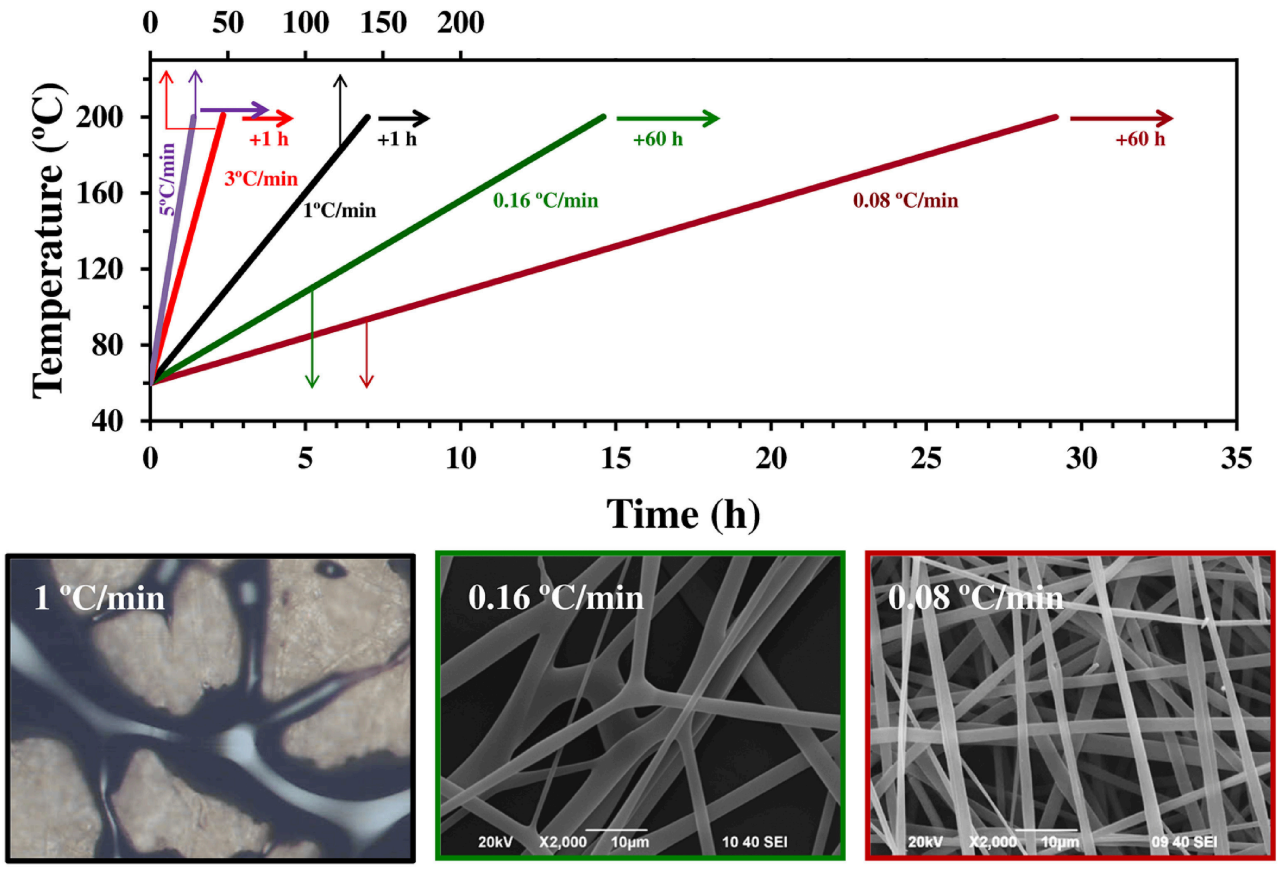

Stabilized pure lignin fibers

FIGURE 5 | Effect of the heating rate on the stabilization of pure and P-containing lignin fibers.

C-O-P bonds. A further increase of oxygen is observed after stabilization step (29.5\%). These bonds seem to be related to the presence of different phosphates (and/or polyphosphates) groups that are responsible of the cross-linking of the polymeric chains of lignin, allowing the air stabilization to be carried out at faster rate. The cross-linking and condensation attained at this stage is sufficient to proceed with the direct carbonization of the lignin fibers (i.e., avoiding the air stabilization step) without melting of the fibers if a low heating rate $\left(1^{\circ} \mathrm{C} / \mathrm{min}\right)$ is used. Figure 5 shows the effect of the heating rate in the stabilization of pure and $\mathrm{P}$-containing lignin fibers. For the latest, high heating rates as high as $3^{\circ} \mathrm{C} / \mathrm{min}$ are used without producing the melting of the fibers, while a heating rate of $5^{\circ} \mathrm{C} / \mathrm{min}$ can be employed to provide interconnected lignin fibers. Only relatively short times $(1 \mathrm{~h})$ during the isothermal stabilization temperature at $200^{\circ} \mathrm{C}$ are required when using high heating rates in the stabilization step to complete it, preventing the fusion of the fibers in the next carbonization step at $900^{\circ} \mathrm{C}$ with a heating rate of $10^{\circ} \mathrm{C} / \mathrm{min}$. In contrast, much longer times are necessary for pure lignin fibers, during the stabilization step to prevent the fusion. A heating rate of $1^{\circ} \mathrm{C} / \mathrm{min}$ produces the complete fusion of the lignin fibers (Figure 5), meanwhile values as low as $0.16^{\circ} \mathrm{C} / \mathrm{min}$ provide interconnected-lignin fibers. In fact, the heating rate is 35 times slower than that for the P-containing lignin fibers $\left(0.08 \mathrm{vs} .3^{\circ} \mathrm{C} / \mathrm{min}\right)$ and the total stabilization time of the fibers including the isothermal step is 50 times longer than that for the P-containing lignin fibers.

In addition to the advantages shown by $\mathrm{H}_{3} \mathrm{PO}_{4}$ on the lignin fibers stabilization, some others are also found in the resulting carbonized fibers. First of all, it is known that the preparation of carbon materials by chemical activation with $\mathrm{H}_{3} \mathrm{PO}_{4}$ increase the preparation yield due to the restriction of 
tars formation and the dehydration of the lignin structure (Rosas et al., 2009). A preparation yield around $40 \%$ was found for the preparation of phosphorus carbon fibers at $900^{\circ} \mathrm{C}$, being much higher than that obtained for pure carbon fibers (yield $=27 \%$ ). Microporous carbon fibers were obtained by direct carbonization of pure stabilized lignin fibers with a specific surface area $\left(\mathrm{S}_{\mathrm{BET}}\right)$ of $850 \mathrm{~m}^{2} / \mathrm{g}$. Comparing the micropore volumes obtained from $\mathrm{N}_{2}$ and $\mathrm{CO}_{2}$ adsorption at -196 and $0^{\circ} \mathrm{C}$, respectively, it is possible to find a relation of $\mathrm{V}_{\mathrm{t}}^{\mathrm{N} 2} / \mathrm{V}_{\mathrm{DR}}^{\mathrm{CO} 2}$ of 0.82 , which indicates the predominance of narrow microporosity. The chemical composition of pure carbon fibers, obtained by XPS, was 96.3 and $3.7 \%$ of carbon and oxygen, respectively. Chemical activation with $\mathrm{H}_{3} \mathrm{PO}_{4}$ is used to prepare carbon materials with a well-porosity development in the micro-mesopore range, whose results depend on the impregnation ratio and activation temperature (Rosas et al., 2009; Bedia et al., 2011). With the addition of a $30 \%$ wt of $\mathrm{H}_{3} \mathrm{PO}_{4}$ (with respect to lignin) in the lignin solution, carbon fibers with $1,345 \mathrm{~m}^{2} / \mathrm{g}$ of specific surface area $\left(\mathrm{S}_{\mathrm{BET}}\right)$ were obtained. For phosphorus containing carbon fibers, a micropore volume of $0.58 \mathrm{~cm}^{3} / \mathrm{g}$ is observed from $\mathrm{N}_{2}$ adsorption isotherm. A lower value of narrow micropore volume $\left(0.412 \mathrm{~cm}^{3} / \mathrm{g}\right)$ was obtained, indicating that the addition of $\mathrm{H}_{3} \mathrm{PO}_{4}$ widens the microporosity of carbonized fibers. In this case, higher amount of oxygen $(7.7 \% \mathrm{wt}$ ) was detected on the carbon fibers surface due to the presence of C-O-P bonds from the phosphate groups. Furthermore, the presence of thermally stable C-O-P groups on the lignin fibers is responsible for the high oxidation resistance of these materials. This interesting feature allows to selectively gasify with diluted oxygen $(3 \% \mathrm{v})$ at temperatures of $900^{\circ} \mathrm{C}$, showing carbon fibers with a specific surface area of $2,000 \mathrm{~m}^{2} / \mathrm{g}$. Carbonization in the presence of diluted $\mathrm{O}_{2}$ develops wider micropores (relation between $\mathrm{V}_{\mathrm{t}}^{\mathrm{N} 2} / \mathrm{V}_{\mathrm{DR}}^{\mathrm{CO} 2}$ of 2) and even mesopores $\left(\mathrm{V}_{\text {mesopores }} 0.107 \mathrm{~cm}^{3} / \mathrm{g}\right)$. As for the surface chemistry of gasified carbon fibers, an increase up to $16 \%$ wt of the oxygen content is detected. Finally, the amount of phosphorus increases from 1.8 to $2.8 \% \mathrm{wt}$, when the fibers are carbonized in presence of diluted oxygen.

The pore size distribution (PSD) of the carbon fibers prepared by direct carbonization, chemical and physical/chemical activation is presented in Figure 6. PSDs are drawn from $\mathrm{N}_{2}$ adsorption data by applying a 2D-NLDFT heterogeneous surface model. The most frequent pore size for carbon fibers prepared by direct carbonization is $5.8 \AA$. In accordance to the $\mathrm{N}_{2} / \mathrm{CO}_{2}$ micropore volume ratios, the addition of $\mathrm{H}_{3} \mathrm{PO}_{4}$ produce carbon fibers with wider porosity after carbonization, shifting the maximum of the PSD to $6.3 \AA$ and delivering the appearance of new micorpores of sizes around $13 \AA$. In the case of chemical activation in presence of diluted oxygen, a bimodal pore size distribution, with the maximum of pore sizes at 6.8 and $16 \AA$, is observed.

A brief summary of the fiber diameter $(\varnothing)$ and specific surface areas of carbon fibers prepared from different types of lignin and experimental conditions is collected in Table 1. In general, carbonization of pure lignin fibers produces carbon fibers with a low porosity development, being the surface areas values higher when Alcell lignin is used as raw material. The use of chemical agents in the initial lignin solutions $(\mathrm{KOH}, \mathrm{NaOH}$

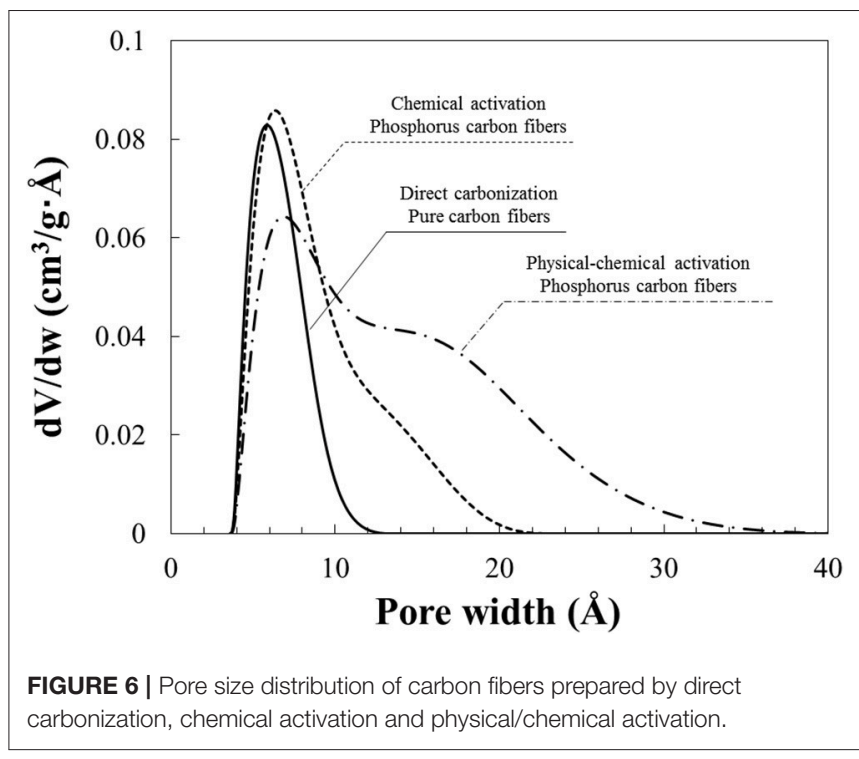

and $\mathrm{H}_{3} \mathrm{PO}_{4}$ ) produces an increase in the porosity development. The highest surface area, 2,000 $\mathrm{m}^{2} / \mathrm{g}$, of the carbon fibers prepared in one step (referred to the carbonization/activation step) is obtained when chemical activation is carried out under diluted air flow. Two steps preparation of lignin carbon fibers (marked with * in Table 1), consisting of carbonization followed by partial gasification of the fibers, provide carbon fibers with similar apparent surface areas to that obtained by our research group in only one step, only overpassed by those obtained by Lin et al. (2012).

The preparation of phosphorus containing carbon fibers has a great importance in catalysis, adsorption and electrochemical applications. For instance, phosphorus containing carbon fibers have been used as catalysts for the alcohol decomposition reaction, which is used to evaluate the acid/basic properties of the catalyst. A positive relationship between the catalyst activity in 2propanol decomposition and the $\mathrm{P}$ content in the carbon fibers was found. The 2-propanol decomposition on the P-containing carbon fibers showed selectivity to propylene of $100 \%$, evidencing the acid character of these carbon fibers. Moreover, the Pcontaining carbon fibers with the highest $\mathrm{P}$ surface amount show similar catalytic activity than that obtained for a commercial acid catalyst $\left(\gamma-\mathrm{Al}_{2} \mathrm{O}_{3}\right)$. On the other hand, when pure carbon fibers were used as catalyst for 2-propanol decomposition, high selectivity to acetone was obtained, suggesting the basic character of these catalysts. In addition, pure carbon fibers showed high oxidation resistance by itself, combusting at temperatures higher than $500^{\circ} \mathrm{C}$ in presence of oxygen. However, phosphorus containing carbon fibers have even higher oxidation resistance, starting to burnt-off at temperatures near to $525-550^{\circ} \mathrm{C}$. Psurface groups, that are thermally stable at high temperature, are the responsible for the increase of the oxidation resistance of these carbon fibers, as previously mentioned (Wu and Radovic, 2006; Rosas et al., 2012; Valero-Romero et al., 2017). The textural properties, physico-chemical properties, morphology and small sizes of these fibers are very attractive to use these materials 
TABLE 1 | Specific surface areas of carbon fibers prepared from different types of lignin.

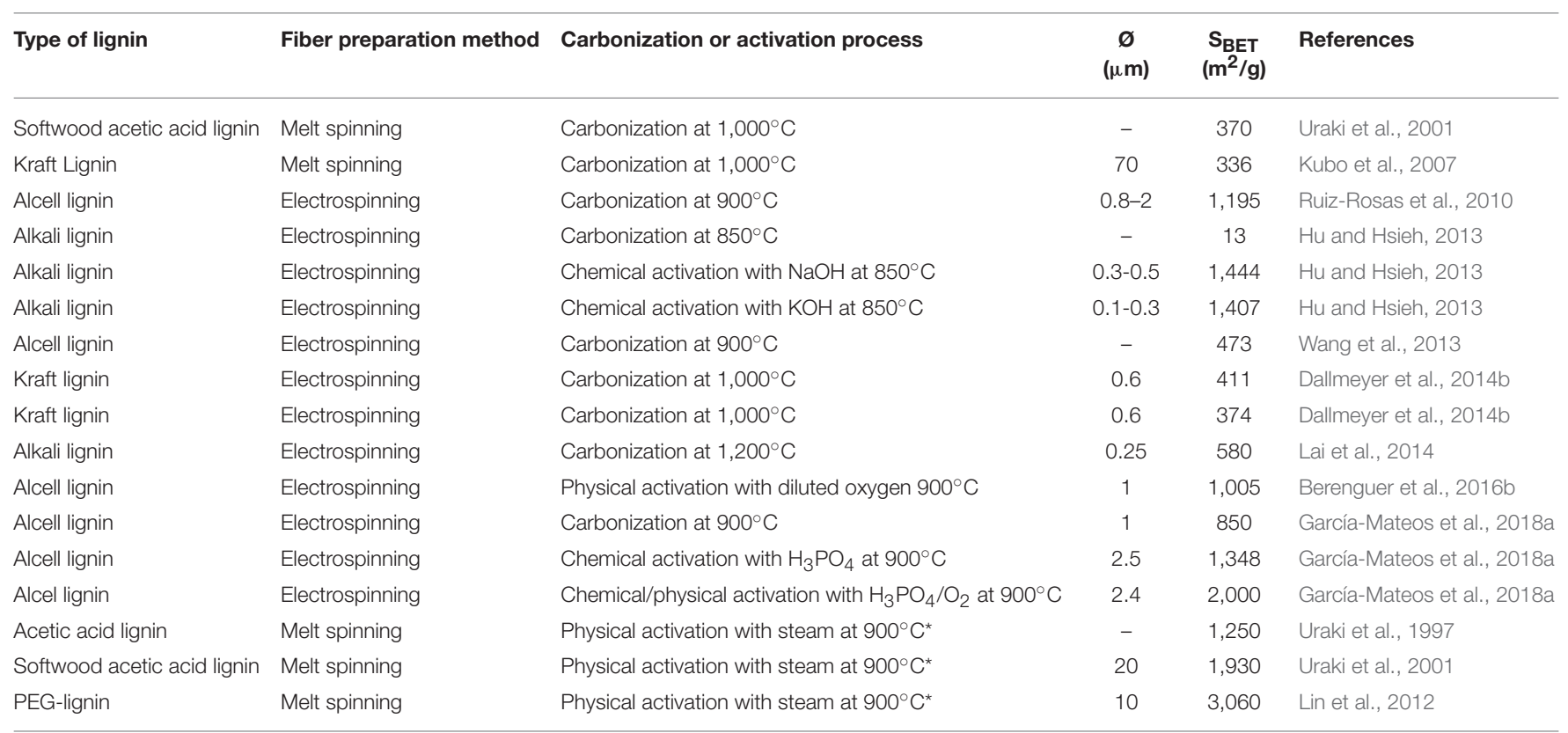

${ }^{\star}$ Two-step activated carbon fibers preparation (carbonization and physical activation).

as adsorbent in liquid phase. Phosphorus carbon fibers present high phenol adsorption capacities, around $180 \mathrm{mg}$ of phenol per gram of adsorbent, with an equilibrium phenol concentration of $25 \mathrm{mg} / \mathrm{L}$ at $25^{\circ} \mathrm{C}$. Finally, the P-containing carbon fibers were also evaluated as binderless carbon electrodes. We have already mentioned that carbonization at $900^{\circ} \mathrm{C}$ provides a high structural order and, in consequence, a high electrical conductivity to carbonized lignin fibers (Berenguer et al., 2016b). P-containing carbon fibers also showed promising result in electrochemical applications as supercapacitors, especially duet to their high stability, which allow them to operate safely in wide potential windows for different electrolytes $(\Delta \mathrm{E}=1.6$, 1.65 and 1.9 for $\mathrm{H}_{2} \mathrm{SO}_{4}, \mathrm{NaOH}$, and $\mathrm{Na}_{2} \mathrm{SO}_{4}$, respectively). Again, the presence of phosphorus groups strongly bonded to the carbon surface improve the electro-oxidation resistance of these materials, probably due to the deactivating effect of these groups in the electrochemical water decomposition reaction (Berenguer et al., 2015).

\section{One-Pot Synthesis Preparation of Metal-Containing Lignin-Based Electrocatalysts}

Carbon materials are widely used as catalyst support for the dispersion of metallic nanoparticles acting as the active phase of different catalytic and electrocatalytic reactions (Liu et al., 2004; Cordero-Lanzac et al., 2017). The methodology most commonly used for the preparation of conventional carbon-based catalysts can be divided into different steps (Rosas et al., 2010; Berenguer et al., 2016a); (i) preparation of carbon support, (ii) impregnation with the metallic solution by wet impregnation routes, and (iii) stabilization of the active phase. The use of electrospinning for the preparation of metal-decorated carbon fibers is a new method that simplifies the preparation process of catalysts.

In our research group, we have reported the one-pot preparation of $\mathrm{Pt}$ supported lignin-based carbon fibers in a simple way by using electrospinning technique (García-Mateos et al., 2017). In this work, different amounts of platinum acetylacetonate (Pt salt:lignin 0.006 and 0.03 ) were added to the spinnable lignin/ethanol or $\mathrm{H}_{3} \mathrm{PO}_{4}$ /lignin/ethanol solution with the objective to obtain Pt-containing lignin fibers in one step with low and high Pt content ( 1 and 5\% wt. Pt, respectively, in the final carbon electrocatalysts). After stabilization and carbonization of the $\mathrm{H}_{3} \mathrm{PO}_{4}$-free carbon fibers, carbon fibers electrocatalysts with well-dispersed platinum nanoparticles were obtained, although the preparation yields decreased with the platinum loading, being between 10 and 30\%. This drawback was overcome when phosphoric acid was included in the solution. Similar stabilization and carbonization yields were obtained regardless the amount of platinum acetylacetonate used (yield of 88 and $33 \%$ for stabilization and carbonization, respectively). These results can be related with the high activity of $\mathrm{Pt}$ for gasification reactions, which are reduced in the case of $\mathrm{P}$-containing lignin fibers, due to the presence of C-O-P groups.

The incorporation of $\mathrm{Pt}$ precursor to the lignin solutions has a strong influence on the porous texture of pure carbon fibers. Pure carbon fibers without $\mathrm{Pt}$ are microporous materials with a specific surface area of $851 \mathrm{~m}^{2} / \mathrm{g}$. The increase of the Pt content produces a development of the mesoporosity. For the final carbon fibers electrocatalysts with low and high Pt content, specific surface areas of around $760 \mathrm{~m}^{2} / \mathrm{g}$ were obtained, but an increase of the external surface area (from 161 to $383 \mathrm{~m}^{2} / \mathrm{g}$ ) and mesopore volume (from 0.24 to $0.51 \mathrm{~cm}^{3} / \mathrm{g}$ ) are produced as the Pt content increases. These results are in concordance with the effect of 
$\mathrm{Pt}$ as gasification promoter. For P-containing carbon fibers the gasification is prevented by the presence of C-O-P groups and a typical isotherm for microporous materials is obtained in all the cases, regardless of the amount of platinum used. Only a slightly increase in the specific surface area is attained as Pt loading increases (from 1,210 to $1,289 \mathrm{~m}^{2} / \mathrm{g}$ ).

Figure 7 shows the SEM images of the carbon fibers catalysts. It can be appreciated that the addition of different quantities of Pt precursor does not modify the roughness of the carbon fibers.

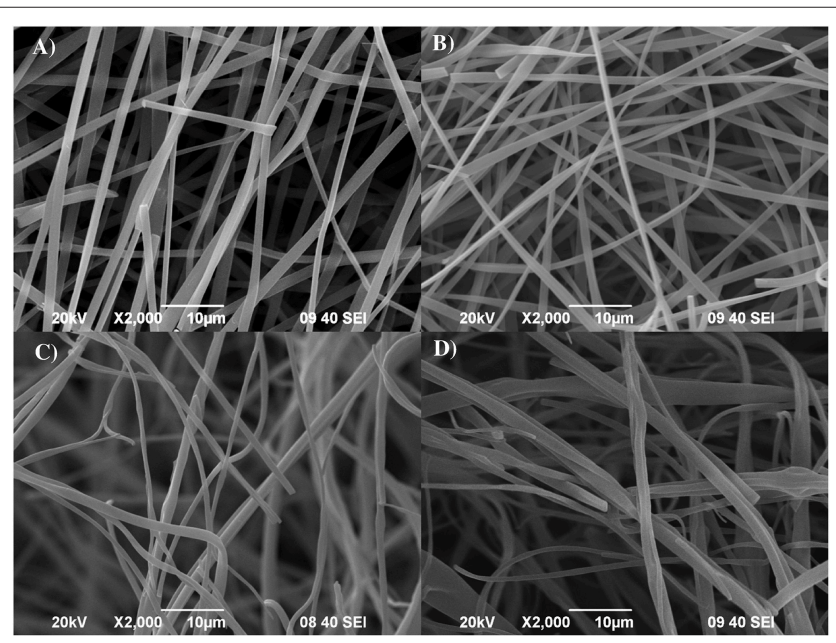

FIGURE 7 | SEM micrographs of (A,B) CFs with 1 and $5 \%$ of Pt, respectively; and (C,D) PCFs with 1 and $5 \%$ of Pt, respectively.
The size of the Pt supported carbon fibers catalysts ranged from 0.6 to $1 \mu \mathrm{m}$ for pure carbon fibers and from 0.6 to $3 \mu \mathrm{m}$ for P-containing carbon fibers.

TEM images of the Pt-decorated carbon fibers shown in Figure 8 confirmed the presence of well-dispersed platinum nanoparticles in the carbonized fibers, no matter the addition of phosphoric acid into the starting solution. These results evidence the usefulness of electrospinning in the preparation of metal loaded carbon fibers through a simple procedure. Phosphoruscontaining carbon fibers exhibit lower Pt particles sizes and narrower particles sizes distribution than pure carbon fibers (mean particle size of 2.8 and $2.1 \mathrm{~nm}$ for low and high Pt content for P-containing carbon fibers, respectively, in front of 5.6 and $9.6 \mathrm{~nm}$ for pure carbon fibers).

Another effect related to the addition of phosphoric acid was revealed during the XPS analyses. The chemical surface compositions obtained from XPS are presented in Figure 9. They confirmed the presence of carbon, oxygen, platinum and phosphorus (the latest only in the P-containing carbon fibers). On the one hand, the oxygen content remains similar, for carbon fibers without the presence of phosphorus, no matter the platinum concentration. On the other hand, P-containing carbon fibers catalysts show higher values of oxygen than the pure ones. In these materials, the oxygen is taken by C-P-O bonds, when platinum is reduced during the thermal treatment, forming new $\mathrm{C}-\mathrm{O}-\mathrm{P}$ bonds, and so increasing the oxygen concentration.

The Pt concentration were 1.0 and $7.1 \%$ wt for low and high Pt content of pure carbon fibers, being close to the nominal Pt loading of the fiber. The deviation observed for the high Pt content in pure carbon fibers may be related to the gasification

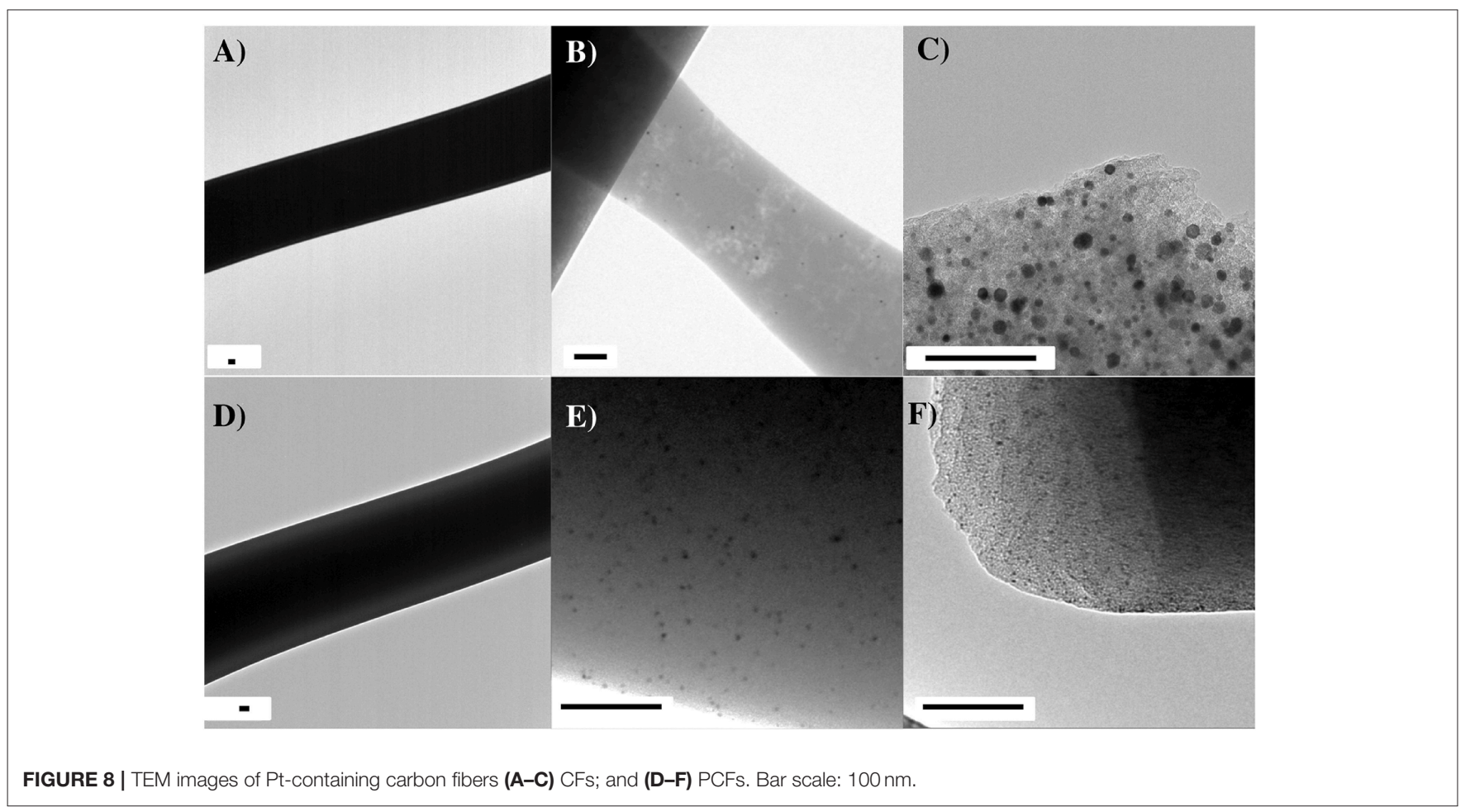




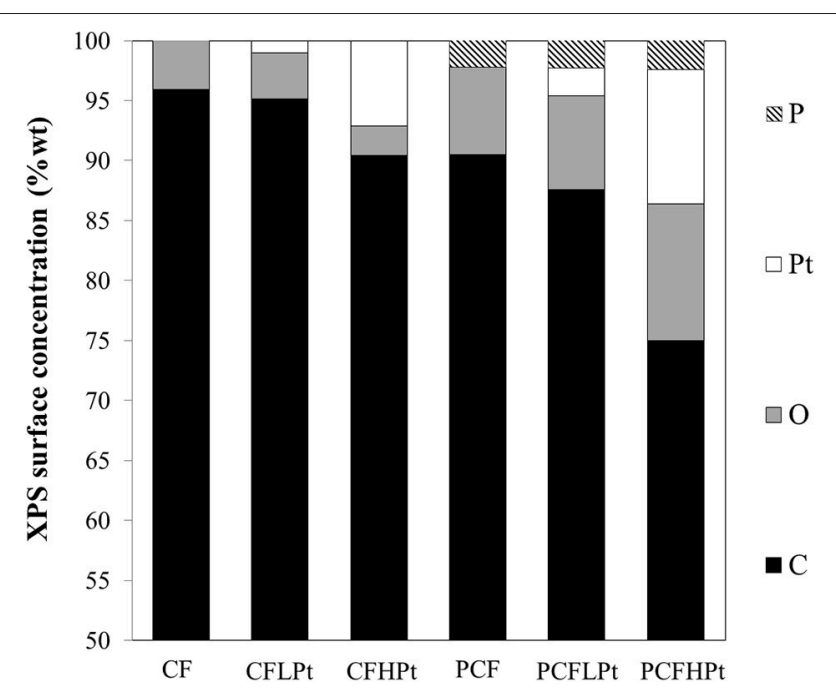

FIGURE 9 | Weight surface concentration of carbon fibers obtained by XPS.

effect of $\mathrm{Pt}$, which was not considered in the formulation of the lignin/salt/ethanol solution. On the contrary, for phosphorus containing carbon fibers, high values of Pt content were obtained by XPS (2.3 and $11.2 \%$ wt for low and high Pt content). Since XPS technique only analyzes the surface of the fibers (around $20 \AA$ deep), these results indicate that Pt is preferable located on the surface of the fibers. Moreover, the detailed analysis of the XPS spectrum in the Pt4f photoemission region revealed the interaction between the P-anions, which favors the presence of $\mathrm{Pt}^{2+}$, restricting the formation of metallic Pt particles and their subsequent sintering. The concentration of phosphorus in carbon fibers remains constant regardless of the Pt amount.

CO-TPD analyses on Figure 10 of pure and Pt-contaning carbon fibers confirm that the presence of platinum renders small modifications to the TPD profiles (black and red profiles in Figure 10). However, the addition of both platinum precursors and phosphoric acid produce a large increase in the amount of surface oxygen groups (blue and green profiles in Figure 10). Furthermore, the $\mathrm{CO}$ release associated to the decomposition of the C-O-P bonds from the phosphate groups (peak at ca. $860^{\circ} \mathrm{C}$ in the blue profile, Figure 10) is shifted to $800^{\circ} \mathrm{C}$, and the temperature onset of the decomposition of surface oxygen groups is lowered from 600 to $400^{\circ} \mathrm{C}$. The decrease in the thermal stability of C-O-P bonds denote the strong interaction between platinum and phosphate groups.

The well-dispersion of all the elements in the carbon fibers was corroborated by EDX mapping showed in Figure 11. As was confirmed by XPS, the mean element presented in the carbon fibers is carbon (more intensity of red color) followed by oxygen (green color). In the case of P-containing carbon fibers, phosphorus is well-distributed in all the fibers. Again, a homogeneous dispersion of $\mathrm{Pt}$ is found on both carbon fibers, which suggests the feasibility of using electrospinning technique to prepare well-dispersed metal decorated carbon fibers.

Taking into account the well-dispersed $\mathrm{Pt}$ nanoparticles on the carbon fibers and their physico-chemical properties,

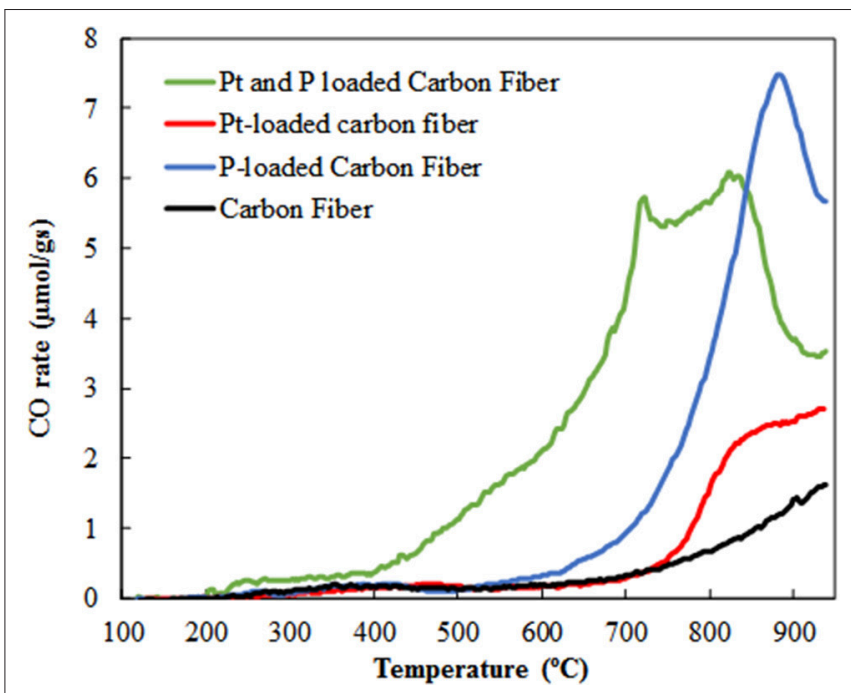

FIGURE 10 | CO-TPD profiles for pure and Pt-containing carbon fibers. Heating rate: $20^{\circ} \mathrm{C} / \mathrm{min}$.

these materials were tested as electrocatalysts for the methanol and ethanol electro-oxidation (MOR and EOR, respectively), reactions of interest for the development of direct alcohol in fuel cells. Owing to their advantageous conformation as continuous carbon cloths, the samples were simply cut in a shape resembling the surface of the collector and attached to it for the electrocatalytic tests. All the analyzed samples showed catalytic activity (i.e., presence of large oxidation peaks at positive potentials during $\mathrm{CV}$ measurements in a methanol solution in $0.5 \mathrm{M} \mathrm{H}_{2} \mathrm{SO}_{4}$ ), what points out that platinum nanoparticles are reachable by the electrolyte and methanol and active toward the intended reaction. The highest catalytic activity and lower onset potential was obtained for pure carbon fibers with the highest amount of $\mathrm{Pt}$, what could be connected to the presence of a more developed pore structure (easing the access of methanol to the metal nanoparticles) of this sample. This electrocatalyst showed an excellent alcohol electro-oxidation performance, starting to oxidize methanol at $0.40 \mathrm{~V}$ vs. $\mathrm{Ag} / \mathrm{AgCl}$. The ratio of the forward $\left(\mathrm{I}_{\mathrm{f}}\right)$ to reverse $\left(\mathrm{I}_{\mathrm{b}}\right)$ anodic peak current densities was of 1.2, indicating the excellent tolerance of these catalyst toward $\mathrm{CO}$ poisoning. The presence of $\mathrm{P}$ enhances the resistance toward CO poisoning, but a lower catalytic activity was observed. Durability tests at constant potential of $0.6 \mathrm{~V}$ for the most active sample delivered an initial current density value of $495 \mathrm{~A} / \mathrm{g}_{\mathrm{Pt}}$, with ca. $75 \%$ of this value being retained after the first hour of experiment. The electro-activity of the pure carbon fibers with the highest Pt content (the most active one in methanol oxidation) was also evaluated for the ethanol electro-oxidation, obtaining a peak value of current density of $370 \mathrm{~A} / \mathrm{g}_{\mathrm{Pt}}$ in the forward scan at $0.69 \mathrm{~V}$. The exceptional platinum distribution, high dispersion and the excellent charge propagation characteristic of the carbon support due to the high structural order and interconnectivity of the carbon fibers are the responsible for the outstanding performance for methanol and ethanol electro-oxidation. 


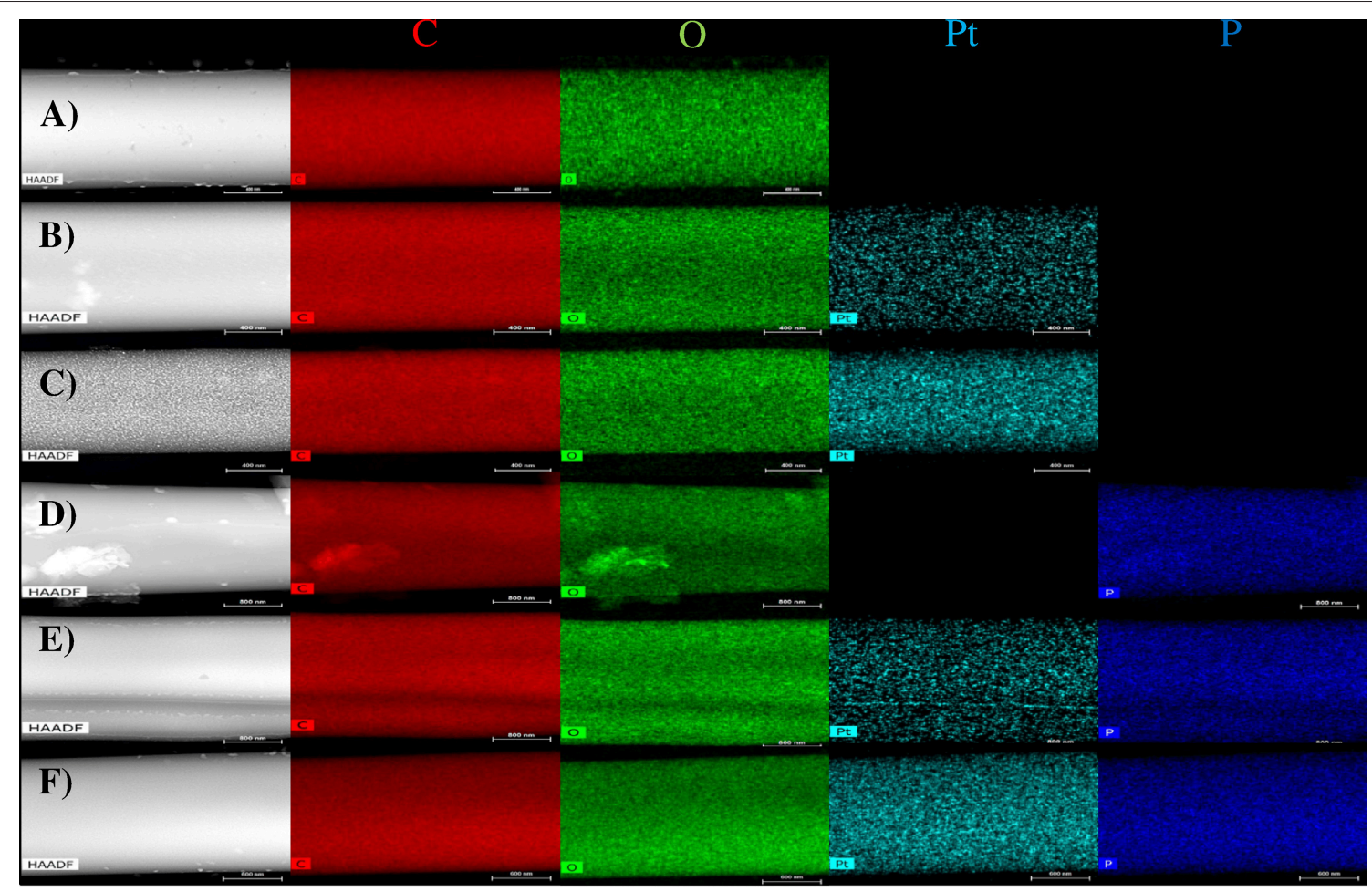

FIGURE 11 | EDX mapping of: free metal, low and high Pt concentration in CFs (A-C), respectively); and PCFs (D-F), respectively).

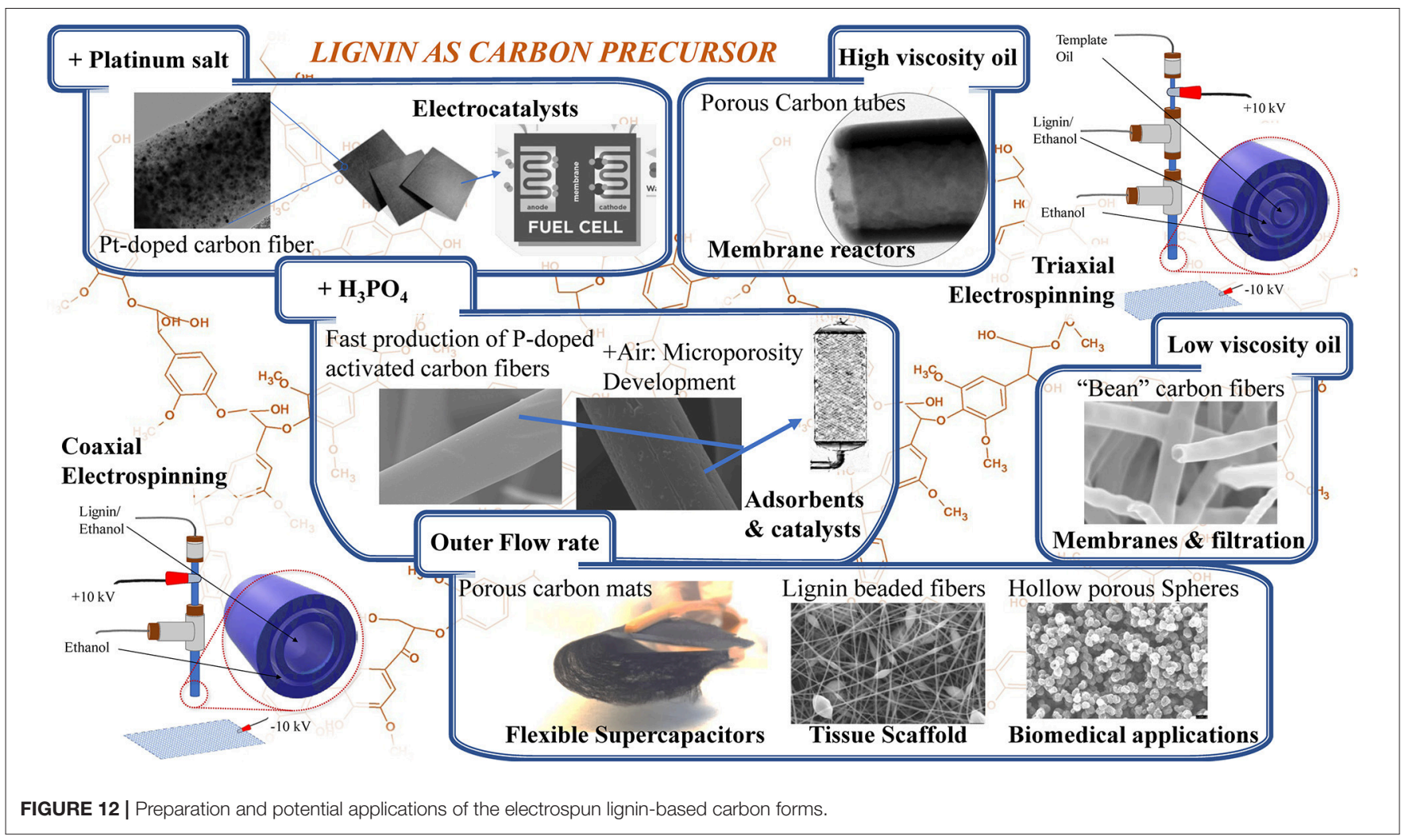


Following the same methodology, our research group is currently working in the preparation of other valuable electrocatalysts using different metals, such as Fe, Co, or Pd, which could replace $\mathrm{Pt}$ in the electrodes of fuel cell devices and help to reduce their production costs. Supported metallic nanoparticles are put into the carbon fibers catalyst by adding different nitrates, chlorides and even acetylacetonate metallic salts to the lignin solution. The presence of these salt precursors during the carbonization step results in a development of the mesoporosity, what is desirable for the intended application. The electrochemical characterization in acid and alkaline electrolyte has confirmed that the metal-containing carbon cloths are promising ORR catalysts that could be useful for reducing the amount of noble metals in the electrodes or for allowing the use of non-noble metals as catalysts (García-Mateos et al., 2018b).

Figure 12 summarizes the different possibilities for the modification of the morphology, surface chemistry and porosity of electrospun lignin-based carbons presented in this work along with their potential applications.

\section{CONCLUSIONS}

The works herein reviewed highlights the advantages brought by the electrospinning of Alcell lignin/ethanol solutions to the production of porous carbon fibers of a large variety of morphologies and compositions. The use of coaxial spinnerets is the key for enabling a steady production of microsized, solid lignin fibers by the addition of a small amount of ethanol through the external needle. No additives for the modification of the viscosity or the surface tension of the solution are needed owing to the high solubility of Alcell lignin in ethanol. Tuning of the ethanol flow rate in the outer needle leads to the selective production of spheres, beaded, or linear fibers. In addition, triaxial configuration enables to prepare lignin tubes using different oils as templates. Shape and sizes of these tubes can be controlled through the relative outer to inner flow rates. The electrospun lignin fibers are collected as a non-woven mat that can be carbonized to produce flexible microporous carbon sub-microfibers (without further porosity development treatments) after a slow thermooxidative step in air. The connectivity of the mat can be also increased by speeding up the thermostabilization process, leading to partial fusion of the fibers. Moreover, the time required for this treatment is greatly shortened when using a silica-lignin composite that maintain the lignin core within a silica shell, avoiding the melting of the fibers, and also when phosphoric acid is added into the lignin solution, catalyzing the crosslinking of the polymeric structure of lignin. In addition, the latter treatment also leads to porosity development. Partial gasification in diluted air during the carbonization step is another valid method for increasing the

\section{REFERENCES}

Ahmed, F. E., Lalia, B. S., and Hashaikeh, R. (2015). A review on electrospinning for membrane fabrication: challenges and applications. Desalination 356, 15-30. doi: 10.1016/j.desal.2014. 09.033 porosity of the fibers. Finally, metal nanoparticles can be casted into the carbon fibers by adding the metallic precursor in the lignin solution, enabling the preparation of carbon-supported catalysts in fibrillary morphology in a one-step procedure.

Due to the combination of high chemical and electrochemical resistance, large specific surface area and porosity development, improved mass transfer rate, high electrical conductivity, good metal dispersion and adequate mechanical properties, these carbon fibers are good candidates for being used in several applications. The composition, surface chemistry and porosity of the lignin-based electrospun materials are tuned for the intended application. In this sense, microporous carbon fibers have an outstanding performance as binderless carbon electrodes, while Pt-loaded meso- and microporous carbon fibers are excellent carbon electrocatalysts for methanol oxidation. Phosphorus containing carbon fibers shows high activity as catalysts in alcohol dehydration reactions because of its high surface acidity, while pure carbon fibers have basic character and promote alcohol dehydrogenation reactions. Finally, microporous carbon fibers have shown large adsorption capacities for the removal of pollutants in aqueous phase. In addition, the introduction of surface roughness and the encapsulation of molecules within the carbon fibers, that can be achieved using the triaxial configuration paves the way to their applications as membranes or for controlled drug delivery. All these results confirm that electrospinning of lignin solution is a promising method for the preparation of a large variety of carbon materials in fibrillary morphologies that show excellent performances as porous carbon catalysts, electrocatalysts, electrodes, and adsorbents.

\section{AUTHOR CONTRIBUTIONS}

FG-M, RR-R, and JR prepared the manuscript. FG-M prepared the carbon fibers, performed the characterization of samples, the catalytic and adsorption test, and the discussion of these results. RR-R performed the electrochemical characterization. JR, JR-M, and TC developed the synthesis concept. All authors discussed the result and commented on the manuscript.

\section{FUNDING}

Ministerio de Economía y Competitividad, Gobierno de España and Fondo Europeo de Desarrollo Regional (FEDER) for CTQ2015-68654-R project.

\section{ACKNOWLEDGMENTS}

This work was supported by the Spanish Ministry of Economy and Competitiveness and FEDER (CTQ2015-68654-R).

Beachley, V., and Wen, X. (2009). Effect of electrospinning parameters on the nanofiber diameter and length. Mater. Sci. Eng. C 29, 663-668. doi: 10.1016/j.msec.2008.10.037

Bedia, J., Barrionuevo, R., Rodríguez-Mirasol, J., and Cordero, T. (2011). Ethanol dehydration to ethylene on acid carbon catalysts. Appl. Catal. B 103, 302-310. doi: 10.1016/j.apcatb.2011.01.032 
Berenguer, R., Fornells, J., García-Mateos, F. J., Guerrero-Pérez, M. O., RodríguezMirasol, J., and Cordero, T. (2016a). Novel synthesis method of porous VPO catalysts with fibrous structure by electrospinning. Catal. Today 277, 266-273. doi: 10.1016/j.cattod.2016.03.002

Berenguer, R., García-Mateos, F. J., Ruiz-Rosas, R., Cazorla-Amorós, D., Morallón, E., Rodríguez-Mirasol, J., et al. (2016b). Biomass-derived binderless fibrous carbon electrodes for ultrafast energy storage. Green Chem. 18, 1506-1515. doi: 10.1039/C5GC02409A

Berenguer, R., Ruiz-Rosas, R., Gallardo, A., Cazorla-Amorós, D., Morallón, E., Nishihara, H., et al. (2015). Enhanced electro-oxidation resistance of carbon electrodes induced by phosphorus surface groups. Carbon 95, 681-689. doi: 10.1016/j.carbon.2015.08.101

Braun, J. L., Holtman, K. M., and Kadla, J. F. (2005). Lignin-based carbon fibers: oxidative thermostabilization of kraft lignin. Carbon 43, 385-394. doi: 10.1016/j.carbon.2004.09.027

Brodin, I., Ernstsson, M., Gellerstedt, G., and Sjöholm, E. (2011). Oxidative stabilisation of kraft lignin for carbon fibre production. Holzforschung 66, 141-147. doi: 10.1515/HF.2011.133

Brown, T. D., Dalton, P. D., and Hutmacher, D. W. (2016). Melt electrospinning today: An opportune time for an emerging polymer process. Prog. Polymer Sci. 56, 116-166. doi: 10.1016/j.progpolymsci.2016.01.001

Cavaliere, S., Subianto, S., Savych, I., Jones, D. J., and Rozière, J. (2011). Electrospinning: designed architectures for energy conversion and storage devices. Energy Environ. Sci. 4, 4761-4785. doi: 10.1039/C1EE02201F

Cloupeau, M., and Prunet-Foch, B. (1994). Electrohydrodynamic spraying functioning modes: a critical review. J. Aerosol Sci. 25, 1021-1036. doi: 10.1016/0021-8502(94)90199-6

Cordero-Lanzac, T., García-Mateos, F. J., Rosas, J. M., Rodríguez-Mirasol, J., and Cordero, T. (2018). Flexible binderless capacitors based on P- and Ncontaining fibrous activated carbons from denim cloth waste. Carbon 139, 599-608. doi: 10.1016/j.carbon.2018.06.060

Cordero-Lanzac, T., Palos, R., Arandes, J. M., Castaño, P., Rodríguez-Mirasol, J., Cordero, T., et al. (2017). Stability of an acid activated carbon based bifunctional catalyst for the raw bio-oil hydrodeoxygenation. Appl. Catal. B 203, 389-399. doi: 10.1016/j.apcatb.2016.10.018

Dallmeyer, I., Ko, F., and Kadla, J. F. (2010). Electrospinning of Technical Lignins for the Production of Fibrous Networks. J. Wood Chem. Technol. 30, 315-329. doi: 10.1080/02773813.2010.527782

Dallmeyer, I., Ko, F., and Kadla, J. F. (2014a). Correlation of elongational fluid properties to fiber diameter in electrospinning of softwood kraft lignin solutions. Ind. Eng. Chem. Res. 53, 2697-2705. doi: 10.1021/ie403724y

Dallmeyer, I., Lin, L. T., Li, Y., Ko, F., and Kadla, J. F. (2014b). Preparation and characterization of interconnected, kraft lignin-based carbon fibrous materials by electrospinning. Macromol. Mater. Eng. 299, 540-551. doi: 10.1002/mame.201300148

Deitzel, J. M., Kleinmeyer, J., Harris, D., and Beck Tan, N. C. (2001). The effect of processing variables on the morphology of electrospun nanofibers and textiles. Polymer 42, 261-272. doi: 10.1016/S0032-3861(00)00250-0

Espinoza-Acosta, J. L., Torres-Chávez, P. I., Olmedo-Martínez, J. L., Vega-Rios, A., Flores-Gallardo, S., and Zaragoza-Contreras, E. A. (2018). Lignin in storage and renewable energy applications: a review. J. Energy Chem. 27, 1422-1438. doi: 10.1016/j.jechem.2018.02.015

Fang, Z., and Smith, R. L Jr. (2016). Production of Biofuels and Chemicals from Lignin. Singapore: Springer. Available online at: //www.springer.com/gp/book/9789811019647 (accessed January 25, 2019).

Fennessey, S. F., and Farris, R. J. (2004). Fabrication of aligned and molecularly oriented electrospun polyacrylonitrile nanofibers and the mechanical behavior of their twisted yarns. Polymer 45, 4217-4225. doi: 10.1016/j.polymer.2004.04.001

Fong, H., Chun, I., and Reneker, D. H. (1999). Beaded nanofibers formed during electrospinning. Polymer 40, 4585-4592. doi: 10.1016/S0032-3861(99)00068-3

Frank, E., Steudle, L. M., Ingildeev, D., Spörl, J. M., and Buchmeiser, M. R. (2014). Carbon fibers: precursor systems, processing, structure, and properties. Angew. Chem. Int. Ed. 53, 5262-5298. doi: 10.1002/anie.201306129

Fukuoka, Y. (1969). Method for producing carbonized lignin fiber. Jpn. Chem. Q. $5,63-66$.
Gañán-Calvo, A. M., Dávila, J., and Barrero, A. (1997). Current and droplet size in the electrospraying of liquids. Scaling laws. J. Aerosol Sci. 28, 249-275. doi: 10.1016/S0021-8502(96)00433-8

García-Mateos, F. J., Berenguer, R., Valero-Romero, M. J., Rodríguez-Mirasol, J., and Cordero, T. (2018a). Phosphorus functionalization for the rapid preparation of highly nanoporous submicron-diameter carbon fibers by electrospinning of lignin solutions. J. Mater. Chem. A. 6, 1219-1233. doi: 10.1039/C7TA08788H

García-Mateos, F. J., Cordero-Lanzac, T., Berenguer, R., Morallón, E., CazorlaAmorós, D., Rodríguez-Mirasol, J., et al. (2017). Lignin-derived Pt supported carbon (submicron)fiber electrocatalysts for alcohol electro-oxidation. Appl. Catal. B. 211, 18-30. doi: 10.1016/j.apcatb.2017.04.008

García-Mateos, F. J., Ruiz-Rosas, R., Ortega, A., Cazorla-Amorós, D., Morallón, E., Rodriguez-Mirasol, J., et al. (2018b). One-pot sinthesys of lignin-based electrospun oxygen reduction reaction electrocatalysts. in Program and Short Abstracts of the Carbon Conference (Madrid).

Gonzalez-Serrano, E., Cordero, T., Rodriguez-Mirasol, J., Cotoruelo, L., and Rodriguez, J. J. (2004). Removal of water pollutants with activated carbons prepared from $\mathrm{H} 3 \mathrm{PO} 4$ activation of lignin from kraft black liquors. Water Res. 38, 3043-3050. doi: 10.1016/j.watres.2004.04.048

Hohman, M. M., Shin, M., Rutledge, G., and Brenner, M. P. (2001). Electrospinning and electrically forced jets. II. Applications. Phys. Fluids 13, 2221-2236. doi: $10.1063 / 1.1384013$

Hosseinaei, Q., and Baker, D. A. (2012). "Electrospun carbon nanofibers from kraft lignin," in Book of Abstracts of the Fiber Society (Boston, MA), 7-9.

Hu, S., and Hsieh, Y.-L. (2013). Ultrafine microporous and mesoporous activated carbon fibers from alkali lignin. J. Mater. Chem. A. 1, 11279-11288. doi: $10.1039 / \mathrm{C} 3 \mathrm{TA} 12538 \mathrm{~F}$

Hu, X., Liu, S., Zhou, G., Huang, Y., Xie, Z., and Jing, X. (2014). Electrospinning of polymeric nanofibers for drug delivery applications. J. Control. Rel. 185, 12-21. doi: 10.1016/j.jconrel.2014.04.018

Huang, Z.-M., Zhang, Y.-Z., Kotaki, M., and Ramakrishna, S. (2003). A review on polymer nanofibers by electrospinning and their applications in nanocomposites. Compos. Sci. Technol. 63, 2223-2253. doi: 10.1016/S0266-3538(03)00178-7

Inagaki, M., Yang, Y., and Kang, F. (2012). Carbon nanofibers prepared via electrospinning. Adv. Mater. 24, 2547-2566. doi: 10.1002/adma.201104940

Jagtoyen, M., and Derbyshire, F. (1998). Activated carbons from yellow poplar and white oak by H3PO4 activation. Carbon 36, 1085-1097. doi: 10.1016/S0008-6223(98)00082-7

Kadla, J. F., Kubo, S., Venditti, R. A., Gilbert, R. D., Compere, A. L., and Griffith, W. (2002). Lignin-based carbon fibers for composite fiber applications. Carbon 40, 2913-2920. doi: 10.1016/S0008-6223(02)00248-8

Kenry, and Lim, C. T. (2017). Nanofiber technology: current status and emerging developments. Progress Polymer Sci. 70, 1-17. doi: 10.1016/j.progpolymsci.2017.03.002

Kubo, S., Yoshida, T., and Kadla, J. F. (2007). Surface Porosity of Lignin/PP Blend Carbon Fibers. J. Wood Chem. Technol. 27, 257-271. doi: $10.1080 / 02773810701702238$

Lai, C., Zhou, Z., Zhang, L., Wang, X., Zhou, Q., Zhao, Y., et al. (2014). Freestanding and mechanically flexible mats consisting of electrospun carbon nanofibers made from a natural product of alkali lignin as binder-free electrodes for high-performance supercapacitors. J. Power Sour. 247, 134-141. doi: 10.1016/j.jpowsour.2013.08.082

Lallave, M., Bedia, J., Ruiz-Rosas, R., Rodríguez-Mirasol, J., Cordero, T., Otero, J. C., et al. (2007). Filled and hollow carbon nanofibers by coaxial electrospinning of alcell lignin without binder polymers. Adv. Mater. 19, 4292-4296. doi: 10.1002/adma.200700963

Lannutti, J., Reneker, D., Ma, T., Tomasko, D., and Farson, D. (2007). Electrospinning for tissue engineering scaffolds. Mater. Sci. Eng. C 27, 504-509. doi: 10.1016/j.msec.2006.05.019

Larsen, G., Velarde-Ortiz, R., Minchow, K., Barrero, A., and Loscertales, I. G. (2003). A method for making inorganic and hybrid (organic/inorganic) fibers and vesicles with diameters in the submicrometer and micrometer range via sol-gel chemistry and electrically forced liquid jets. J. Am. Chem. Soc. 125, 1154-1155. doi: $10.1021 / \mathrm{ja} 028983 \mathrm{i}$ 
Leitten, C. F., Griffith, W. L., Compere, A. L., and Shaffer, J. T. (2002). High-Volume, low-cost precursors for carbon fiber production. SAE Trans. 111, 727-734. doi: 10.4271/2002-01-1907

Lin, J., Kubo, S., Yamada, T., Koda, K., and Uraki, Y. (2012). Chemical thermostabilization for the preparation of carbon fibers from softwood lignin. BioResources 7, 5634-5646. doi: 10.15376/biores.7.4.5634-5646.

Liu, Z., Ling, X. Y., Su, X., and Lee, J. Y. (2004). Carbon-supported $\mathrm{Pt}$ and PtRu nanoparticles as catalysts for a direct methanol fuel cell. J. Phys. Chem. B 108, 8234-8240. doi: 10.1021/jp04 $9422 \mathrm{~b}$

Loscertales, I. G., Barrero, A., Guerrero, I., Cortijo, R., Marquez, M., and GañánCalvo, A. M. (2002). Micro/Nano encapsulation via electrified coaxial liquid jets. Science 295, 1695-1698. doi: 10.1126/science.1067595

Mikawa, S. (1970). Lignin-based carbon fiber. Chem. Econ. Eng. Rev. 2, 43-46.

Miller, J. R. (2016). Engineering electrochemical capacitor applications. J. Power Sour. 326, 726-735. doi: 10.1016/j.jpowsour.2016.04.020

Mit-uppatham, C., Nithitanakul, M., and Supaphol, P. (2004). Ultrafine electrospun polyamide- 6 fibers: effect of solution conditions on morphology and average fiber diameter. Macromol. Chem. Phys. 205, 2327-2338. doi: 10.1002/macp.200400225

Norberg, I., Nordström, Y., Drougge, R., Gellerstedt, G., and Sjöholm, E. (2013). A new method for stabilizing softwood kraft lignin fibers for carbon fiber production. J. Appl. Polymer Sci. 128, 3824-3830. doi: 10.1002/app.38588

Pan, H., Li, L., Hu, L., and Cui, X. (2006). Continuous aligned polymer fibers produced by a modified electrospinning method. Polymer 47, 4901-4904. doi: 10.1016/j.polymer.2006.05.012

Ragauskas, A. J., Beckham, G. T., Biddy, M. J., Chandra, R., Chen, F., Davis, M. F., et al. (2014). Lignin valorization: improving lignin processing in the biorefinery. Science 344:1246843. doi: 10.1126/science.1246843

Rodríguez-Mirasol, J., Cordero, T., and Rodríguez, J. J. (1996). High-temperature carbons from kraft lignin. Carbon 34, 43-52. doi: 10.1016/0008-6223(95)00133-6

Rosas J. M., Rodríguez-Mirasol, J., and Cordero, T. (2010). NO Reduction on carbon-supported chromium catalysts. Energy Fuels 24, 3321-3328. doi: 10.1021/ef901455v

Rosas, J. M., Bedia, J., Rodríguez-Mirasol, J., and Cordero, T. (2008). Preparation of hemp-derived activated carbon monoliths. Adsorpt. Water Vapor. Indus. Eng. Chem. Res. 47, 1288-1296. doi: 10.1021/ie070924w

Rosas, J. M., Bedia, J., Rodríguez-Mirasol, J., and Cordero, T. (2009). HEMPderived activated carbon fibers by chemical activation with phosphoric acid. Fuel 88, 19-26. doi: 10.1016/j.fuel.2008.08.004

Rosas, J. M., Berenguer, R., Valero-Romero, M. J., Rodríguez-Mirasol, J., and Cordero, T. (2014). Preparation of different carbon materials by thermochemical conversion of lignin. Front. Mater. 1:29. doi: $10.3389 /$ fmats. 2014.00029

Rosas, J. M., Ruiz-Rosas, R., Rodríguez-Mirasol, J., and Cordero, T. (2012). Kinetic study of the oxidation resistance of phosphorus-containing activated carbons. Carbon 50, 1523-1537. doi: 10.1016/j.carbon.2011. 11.030

Ruiz-Rosas, R., Bedia, J., Barrero, A., Loscertales, I. G., Rodríguez-Mirasol, J., and Cordero, T. (2009). "Lignin-based electrospun carbon submicrotubes and submicroforms," in Annual World Conference on Carbon 2009 (Biarritz), 14-19.
Ruiz-Rosas, R., Bedia, J., Lallave, M., Loscertales, I. G., Barrero, A., RodríguezMirasol, J., et al. (2010). The production of submicron diameter carbon fibers by the electrospinning of lignin. Carbon 48, 696-705. doi: 10.1016/j.carbon.2009.10.014

Sabantina, L., Rodríguez-Cano, M. Á., Klöcker, M., García-Mateos, F. J., TerneroHidalgo, J. J., Mamun, A., et al. (2018). Fixing PAN Nanofiber Mats during Stabilization for Carbonization and Creating Novel Metal/Carbon Composites. Polymers 10:735. doi: 10.3390/polym10070735

Son, W. K., Youk, J. H., Lee, T. S., and Park, W. H. (2004). The effects of solution properties and polyelectrolyte on electrospinning of ultrafine poly(ethylene oxide) fibers. Polymer 45, 2959-2966. doi: 10.1016/j.polymer.2004.03.006

Tan, S.-H., Inai, R., Kotaki, M., and Ramakrishna, S. (2005). Systematic parameter study for ultra-fine fiber fabrication via electrospinning process. Polymer 46, 6128-6134. doi: 10.1016/j.polymer.2005.05.068

Teo, W. E., and Ramakrishna, S. (2006). A review on electrospinning design and nanofibre assemblies. Nanotechnology 17, R89-R106. doi: 10.1088/0957-4484/17/14/R01

Uraki, Y., Kubo, S., Kurakami, H., and Sano, Y. (1997). Activated carbon fibers from acetic acid lignin. Holzforschung 51, 188-192. doi: 10.1515/hfsg.1997.51.2.188

Uraki, Y., Nakatani, A., Kubo, S., and Sano, Y. (2001). Preparation of activated carbon fibers with large specific surface area from softwood acetic acid lignin. J. Wood Sci. 47, 465-469. doi: 10.1007/BF00767899

Valero-Romero, M. J., García-Mateos, F. J., Rodríguez-Mirasol, J., and Cordero, T. (2017). Role of surface phosphorus complexes on the oxidation of porous carbons. Fuel Process. Technol. 157, 116-126. doi: 10.1016/j.fuproc.2016. 11.014

Wang, S.-X., Yang, L., Stubbs, L. P., Li, X., and He, C. (2013). LigninDerived fused electrospun carbon fibrous mats as high performance anode materials for lithium ion batteries. ACS Appl. Mater. Interfaces 5, 12275-12282. doi: 10.1021/am4043867

Wang, X., Lu, X., Liu, B., Chen, D., Tong, Y., and Shen, G. (2014). Flexible energy-storage devices: design consideration and recent progress. Adv. Mater. 26, 4763-4782. doi: 10.1002/adma.201400910

Wu, X., and Radovic, L. R. (2006). Inhibition of catalytic oxidation of carbon/carbon composites by phosphorus. Carbon 44, 141-151. doi: 10.1016/j.carbon.2005.06.038

Xue, J., Xie, J., Liu, W., and Xia, Y. (2017). Electrospun nanofibers: new concepts, materials, and applications. Acc. Chem. Res. 50, 1976-1987. doi: 10.1021/acs.accounts.7b00218

Conflict of Interest Statement: The authors declare that the research was conducted in the absence of any commercial or financial relationships that could be construed as a potential conflict of interest.

Copyright (C) 2019 García-Mateos, Ruiz-Rosas, Rosas, Rodríguez-Mirasol and Cordero. This is an open-access article distributed under the terms of the Creative Commons Attribution License (CC BY). The use, distribution or reproduction in other forums is permitted, provided the original author(s) and the copyright owner(s) are credited and that the original publication in this journal is cited, in accordance with accepted academic practice. No use, distribution or reproduction is permitted which does not comply with these terms. 